Article

\title{
Assessment of BRDF Impact on VIIRS DNB from Observed Top-of-Atmosphere Reflectance over Dome C in Nighttime
}

\author{
Jinjin Li ${ }^{1,2}$, Shi Qiu ${ }^{1, *}$, Yu Zhang ${ }^{1}$, Benyong Yang ${ }^{3}$, Caixia Gao ${ }^{1}$, Yonggang Qian ${ }^{1}$, , Yaokai Liu ${ }^{1}$ \\ and Yongguang Zhao ${ }^{1}$ \\ 1 Key Laboratory of Quantitative Remote Sensing Information Technology, \\ Aerospace Information Research Institute, Chinese Academy of Sciences, Beijing 100094, China; \\ lijinjin18@mails.ucas.ac.cn (J.L.); zhangyu101475@aircas.ac.cn (Y.Z.); gaocaixia@aoe.ac.cn (C.G.); \\ qianyg@aircas.ac.cn (Y.Q.); liuyk@aircas.ac.cn (Y.L.); zhaoyg@aircas.ac.cn (Y.Z.) \\ 2 School of Optoelectronics, University of Chinese Academy of Sciences, Beijing 100049, China \\ 3 Anhui Institute of Optics and Fine Mechanics, Hefei Institutes of Physical Science, Chinese Academy of \\ Sciences, Hefei 230031, China; byyang@aiofm.ac.cn \\ * Correspondence: qiushi@aircas.ac.cn; Tel.: +86-139-1073-0269
}

Citation: Li, J.; Qiu, S.; Zhang, Y.; Yang, B.; Gao, C.; Qian, Y.; Liu, Y.; Zhao, Y. Assessment of BRDF Impact on VIIRS DNB from Observed

Top-of-Atmosphere Reflectance over Dome C in Nighttime. Remote Sens. 2021, 13, 301. https://doi.org/ $10.3390 /$ rs13020301

Received: 9 December 2020

Accepted: 12 January 2021

Published: 16 January 2021

Publisher's Note: MDPI stays neutral with regard to jurisdictional claims in published maps and institutional affiliations.

Copyright: (c) 2021 by the authors. Licensee MDPI, Basel, Switzerland. This article is an open access article distributed under the terms and conditions of the Creative Commons Attribution (CC BY) license (https:/ / creativecommons.org/licenses/by/ $4.0 /)$.

\begin{abstract}
The Day-Night Band (DNB) imaging sensor of the Visible Infrared Imaging Radiometer Suite (VIIRS) adds nighttime monitoring capability to the Suomi National Polar-Orbiting Partnership and National Oceanic and Atmospheric Administration 20 weather satellite launched in 2011 and 2017, respectively. Nighttime visible imagery has already found diverse applications, but image quality is often unsatisfactory. In this study, variations in observed top-of-atmosphere (TOA) reflectance were examined in terms of nighttime bidirectional effects. The Antarctica Dome $\mathrm{C}$ ground site was selected due to high uniformity. First, variation of reflectance was characterized in terms of viewing zenith angle, lunar zenith angle, and relative lunar azimuth angle, using DNB data from 2012 to 2020 and Miller-Turner 2009 simulations. Variations in reflectance were observed to be strongly anisotropic, suggesting the presence of bidirectional effects. Then, based on this finding, three popular bidirectional reflectance distribution function (BRDF) models were evaluated for effectiveness in correcting for these effects on the nighttime images. The observed radiance of VIIRS DNB was compared with the simulated radiance respectively based on the three BRDF models under the same geometry. Compared with the RossThick-LiSparseReciprocal (RossLi) BRDF model and Hudson model, the Warren model has a higher correlation coefficient (0.9899-0.9945) and a lower root-mean-square-error (0.0383-0.0487). Moreover, the RossLi BRDF model and Hudson model may have similar effects in the description of the nighttime TOA over Dome $\mathrm{C}$. These findings are potentially useful to evaluate the radiometric calibration stability and consistency of nighttime satellite sensors.
\end{abstract}

Keywords: BRDF; VIIRS DNB; nighttime; TOA reflectance; Dome C; RossLi; Warren; Hudson; daytime

\section{Introduction}

The Visible Infrared Imaging Radiometer Suite (VIIRS) is a key instrument [1] onboard the Suomi National Polar-Orbiting Partnership (S-NPP) and National Oceanic and Atmospheric Administration (NOAA) 20 (formerly Joint Polar Satellite System-1, JPSS-1), launched on 28 October 2011, and 18 November 2017, respectively. To support highquality nighttime-visible imagery, the Day-Night Band (DNB), covering wavelengths from 500 to $900 \mathrm{~nm}$ on VIIRS, has a specified dynamic range spanning seven orders of magnitude, making it capable of detecting Earth scenes under illumination as dim as quarter moon. This range is achieved by a three-gain-stage charge-coupled device (CCD) with four arrays of imaging detectors: the low gain stage (LGS) for daytime, the medium gain stage (MGS) for dawn and dusk, and two redundant high gain stages (HGSs) for nighttime, high gain 
stage A (HGA) and high gain stage B (HGB). Detectors in each of the DNB arrays need to be individually calibrated [2]. The VIIRS DNB sensor is also the first of its kind to provide in-orbit radiometric calibration. However, calibration of DNB is complicated, due to its large dynamic range, ultra-high sensitivity, scan-angle-dependent field of view (FOV), and sensitivity to stray light contamination [3,4]. The calibration uncertainty of the LGS and MGS are $5-10 \%$ and $10-30 \%$, respectively, while the uncertainty of the HGS is over $30 \%$. To improve the quality of DNB nighttime visible imagery, uncertainty of the HGS must be reduced.

The Dome Concordia (Dome C) area $\left(75.1^{\circ} \mathrm{S}, 123.4^{\circ} \mathrm{E}\right)$ on the East Antarctic plateau has been considered as an ideal ground site for calibration and validation of satellite sensors, especially for VIIRS DNB HGS. The site has high reflectance from permanent ice and snow cover, and its surface is spatially very homogeneous with a small slope and low surface roughness. The high reflectance site can reflect most moonlight from the top-of-atmosphere (TOA) and transfer it into the HGS sensors, for low-energy observation. However, while the surface stability and atmospheric conditions at Dome $C$ site offer many advantages for DNB sensor calibration and validation, a major disadvantage is that there is a large diurnal variation in reflectance, due to bidirectional effects.

To compensate for these effects, the bidirectional reflectance distribution function (BRDF) can be used to characterize the geometrical reflecting properties of a reflecting surface. In general, BRDF models correct reflectance variations due primarily to varying incident zenith angle and viewing zenith angle (VZA). Ma et al. [5] conducted the vicarious calibration of S-NPP VIIRS DNB on the basis of the deep convective clouds (DCCs), under lunar illumination, to evaluate the radiometric calibration of DNB HGS at night. However, the bidirectional reflectance of DCC was not taken into account under the criterion of lunar zenith angle (LZA) less than 60 degrees and VZA less than 60 degrees. Furthermore, Cao et al. [6] used the Angular Distribution model to estimate the BRDF effect of the DCCs and applied the reflected lunar radiance at night, from the DCC, for the intercalibration of VIIRS DNB on S-NPP and NOAA-20. However, the applicability of the Angular Distribution model for DCC at night had not been analyzed. In the retrieval of NASA's Black Marble nighttime product suit (VNP46), Roman et al. [7] adopted the RossThick-LiSparseReciprocal (RossLi) BRDF model, to correct the surface BRDF effects caused by varying illumination conditions-namely moonlight and reflected airglow from the Earth's upper atmosphere. They thought RossLi model could capture the wide range of conditions affecting the VIIRS DNB on a global basis. Moreover, all available daytime, atmospherically corrected VIIRS DNB bidirectional reflectances over a multi-data period were collected to establish the analytical solution for the RossLi BRDF model parameter values.

However, existing BRDF models are developed primarily for daytime applications, such as analysis of vegetation [8-11], soil [9], snow [10,12-14], and so on. At Antarctic Dome C site, the illumination differs between day and night. Sunlight is the main light source during the day, while sources of light at night are complex, such as moonlight, airglow, lamplight, starlight, aurora, and so on. As the natural light source at night, the moon is about 250,000 times darker than the sun [15]. Additionally, air temperatures at night at Dome $\mathrm{C}$ site are nearly $55{ }^{\circ} \mathrm{C}$ cooler than the daytime [16]; hence, the daytime and nighttime ground characteristics may be different due to changes in environmental factors. The popular Warren and Hudson models were derived based on in situ daytime measurements over Antarctica Dome C, and the RossLi BRDF model is a widely used kernel-driven model. The applicability of these three BRDF models to nighttime over Dome $\mathrm{C}$ is unknown. Moreover, the specific uncertainty is unclear under the implicit assumption that daytime models are equally applicable to nighttime ones $[6,17]$. Note that, in this article, two BRDF models derived based on in situ near-surface measurements of the snow surface over Antarctica Dome $C$ are named after the model-makers' names (Warren model and Hudson model represents the model of Warren et al. [18] and Hudson et al. [19], respectively). 
Therefore, this study first performed a systematic analysis of angles' influence on nighttime TOA reflectance and then used this analysis to explore the applicability of surface BRDF models to nighttime TOA over Dome C, using DNB data from 2012 to 2020. This paper is organized as follows. Section 2 introduces the data, three surface BRDF models, and a TOA lunar irradiance model. Section 3 introduces the study area and the methodology to simulate nighttime radiance at satellite, using three BRDF models to explore their applicability. Section 4 presents the results and related discussion. Section 5 summarizes the work.

\section{Data and Models}

\subsection{VIIRS DNB}

VIIRS is a key instrument on-board the S-NPP and NOAA-20 which are in sun synchronous orbit of about $824 \mathrm{~km}$. VIIRS is a scanning radiometer with a scanning wide of about $3044 \mathrm{~km}$ (the cross-track direction) and a $12 \mathrm{~h}$ revisit time. Its wavelength ranges from 410 to $12.500 \mathrm{~nm}$. According to its resolution, VIIRS includes 5 high-resolution imagery channels (I-bands), 16 moderate resolution channels (M-bands), and one DNB. The rotating telescope assembly (RTA) mirror on VIIRS reflects radiation onto a set of CCD detectors, and one rotation of the mirror is one scan. M-bands and the DNB have 16 detectors to detect this radiation, and I-bands have 32 detectors with twice the resolution of the M-bands and the DNB [20]. According to its physical properties, VIIRS has 14 reflective solar bands (RSBs), seven thermal emissive bands (TEBs), and one DNB.

The panchromatic DNB on VIIRS has a $750 \mathrm{~m}$ spatial resolution, and a specified dynamic range of about 7 orders of magnitude, from $3 \times 10^{-9} \mathrm{~W} \mathrm{~cm}^{-2} \mathrm{sr}^{-1}$ to $0.02 \mathrm{~W} \mathrm{~cm}^{-2} \mathrm{sr}^{-1}$ [1]. DNB achieves this dynamic range by adopting three gain stages: LGS, MGS, and HGS. The LGS is used to observe daytime scenes. The MGS is used to observe dawn or dusk scenes near the Earth's terminator. The HGS, the average of two identical stages-HGA and HGB-is used to observe nighttime scenes. Moreover, the time delay integration (TDI) of these three gain stages has 1, 3, and 250 pixels to increase signal, respectively [21]. Basic characteristics of VIIRS and DNB are listed in Table 1. More specific details can be found in Liao et al. [1]. Furthermore, the purpose of on-orbit radiometric calibration is to determine the offset and the gain. The offset of each gain stage is determined over a dark Earth scene. The gain of LGS is derived by using the solar diffuser (SD) view, while MGS and HGS saturate when the SD is illuminated. The MGS and HGS gains are calculated based on LGS results, together with the estimated gain ratios of MGS/LGS and HGS/MGS [22].

Table 1. Basic Characteristics of Visible Infrared Imaging Radiometer Suite (VIIRS) and Day-Night Band (DNB) (data with symbol “*” and "***” cite from Liao et al. [1] and Qiu et al. [21], respectively).

\begin{tabular}{|c|c|c|}
\hline & Characteristics & Specification \\
\hline \multirow[t]{5}{*}{ VIIRS } & Orbital altitude $(\mathrm{km}) *$ & 824 \\
\hline & Scanning swath $(\mathrm{km})$ * & 3044 \\
\hline & Revisit time $(\mathrm{h})$ & 12 \\
\hline & Wavelength range (nm) & $410-12,500$ \\
\hline & Bands & $\begin{array}{c}5 \text { I-bands, } 16 \text { M-bands, and } 1 \text { DNB } \\
14 \text { RSBs, } 7 \text { TEBs, and } 1 \text { DNB }\end{array}$ \\
\hline \multirow[t]{6}{*}{ DNB } & Spatial resolution & $\sim 750 \mathrm{~m}$ \\
\hline & Wavelength range $(\mathrm{nm})$ & $500-900$ \\
\hline & Dynamic range $\left(\mathrm{W} \cdot \mathrm{cm}^{-2} \cdot \mathrm{sr}^{-1}\right) *$ & $3 \times 10^{-9}$ to 0.02 \\
\hline & Gains & LGS, MGS, and HGS \\
\hline & Quantization * & 14 bits for HGS, 13 bits for others \\
\hline & Time Delay Integration (TDI) ** & $\begin{array}{c}\text { 1, 3, and } 250 \text { pixels for LGS, MGS, } \\
\text { and HGS, respectively }\end{array}$ \\
\hline
\end{tabular}




\subsection{Ground Measured Surface Reflectance}

The multi-angle ground-measured surface reflectance of Antarctic Dome $\mathrm{C}$ was provided by Hudson et al. [19]. Their experiments were carried out at the top of a $32 \mathrm{~m}$ tower, during the austral summers of 2003-2004 and 2004-2005, which is the period of polar daytime. The measurements were made by using a Field-Spec Pro JR spectroradiometer manufactured by Analytical Spectral Devices (ASD). The ASD recorded the radiance from 350 to $2500 \mathrm{~nm}$, with a $25 \mathrm{~nm}$ resolution. Moreover, the fiber optic input cable to the ASD was mounted in a baffle, limiting its field of view to a $15^{\circ}$ cone. The bidirectional reflectance measurements were made under the solar zenith angle (SZA) from $51.57^{\circ}$ to $87^{\circ}$ and the VZA from $7.5^{\circ}$ to $82.5^{\circ}$, with a $15^{\circ}$ interval. The key characteristics of experiments in Hudson et al. [19] are listed in Table 2. Based on these measurements data, the Hudson model was developed by using the empirical orthogonal functions (EOFs) of the data. Moreover, these measurements were also used to calculate the coefficient of RossLi BRDF model and Warren model in this study.

Table 2. Key characteristics of experiments in Hudson et al. [19].

\begin{tabular}{cc}
\hline Characteristics & Specification \\
\hline Location & The top of a $32 \mathrm{~m}$ tower over Dome C \\
Date & Summers of $2003-2004$ and 2004-2005 \\
Instrument & Analytical Spectral Devices (ASD) \\
wavelength & $350-2400 \mathrm{~nm}, 25 \mathrm{~nm}$ resolution \\
SZA & $51.57^{\circ}-87^{\circ}$ \\
VZA & $7.5^{\circ}-82.5^{\circ}, 15^{\circ}$ resolution \\
Relative solar azimuth & $0^{\circ}-180^{\circ}$ \\
\hline
\end{tabular}

SZA, solar zenith angle; VZA, viewing zenith angle.

\subsection{BRDF Models}

\subsubsection{RossLi BRDF Model}

RossLi BRDF model is a semi-empirical linear kernel-driven BRDF model [23-26]. It defines reflectance as a weighted sum of an isotropic parameter and two kernels, RossThick volume scattering kernel and LiSparse Reciprocal geometric-optical scattering kernel. The volume scattering kernel is derived from radiative transfer models [27], and the geometric-optical scattering kernel is based on surface scattering and geometric shadow-casting theory [28]. Moreover, the parameters in this model have corresponding physical meaning in the simulation of scattering properties of canopies and bare soils [8]. Besides this, the RossLi BRDF model has also been found to be functional when applied to reflectance observed by MODIS and S-NPP VIIRS over the surface of Antarctic Dome C $[17,29,30]$. Furthermore, based on framework and relevant theories of the kernel-driven BRDF model, a snow kernel was developed to better model the anisotropic reflectance of pure snow [14]. What is more, it is also the theoretical basis of the Algorithm for Model Bidirectional Reflectance Anisotropies of the Land Surface (AMBRALS), which has been applied to produce the MODIS global albedo and BRDF product [31,32]. This model is expressed as follows:

$$
R(\theta, \varphi, \phi, \lambda)=f_{\text {iso }}(\lambda)+f_{\text {vol }}(\lambda) \cdot K_{\text {vol }}(\theta, \varphi, \phi, \lambda)+f_{\text {geo }}(\lambda) \cdot K_{g e o}(\theta, \varphi, \phi, \lambda)
$$

where $\theta, \varphi, \phi$, and $\lambda$ represent the SZA, VZA, relative solar azimuth, and wavelength, respectively. As shown in Figure 1, the SZA and VZA are made from the $z$-axis. The solar azimuth angle $\left(\phi_{0}\right)$ and the viewing azimuth angle $\left(\phi_{v}\right)$ are measured clockwise from the north. Moreover, the relative solar azimuth $(\phi)$ is defined as the angle measured clockwise from $\phi_{0}$ to $\phi_{v} . K_{v o l}$ is the RossThick volume scattering kernel, and $K_{g e o}$ is the LiSparse Reciprocal geometric-optical scattering kernel. The $f_{i s o}, f_{\text {vol }}$, and $f_{\text {geo }}$ represent coefficients or weightings of isotropic scattering, volume scattering, and geometric-optical scattering, respectively. 


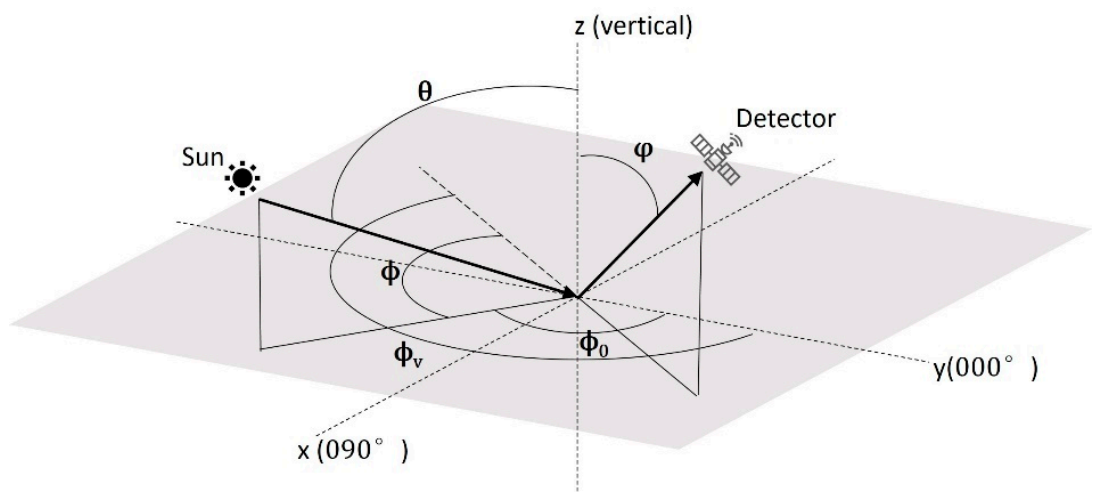

Figure 1. Definition of the solar zenith angle $(\theta)$, the viewing zenith angle $(\varphi)$, the solar azimuth angle $\left(\phi_{0}\right)$, the viewing azimuth angle $\left(\phi_{v}\right)$, and the relative solar azimuth $(\phi)$.

With enough reflectance observations $\rho(\lambda)$ made at angles $\left(\theta_{l}, \varphi_{l}, \phi_{l}\right)$, the analytical solution of this model coefficient, $f_{k}$, is minimization $\partial e^{2} \partial \partial f_{k}=0$ of a least-squares error function [33]:

$$
\begin{gathered}
e^{2}(\lambda)=\frac{1}{d} \sum_{l} \frac{\left(\rho\left(\theta_{l}, \varphi_{l}, \phi_{l}, \lambda\right)-R\left(\theta_{l}, \varphi_{l}, \phi_{l}, \lambda\right)\right)^{2}}{\omega_{l}(\lambda)} \\
f_{k}(\lambda)=\sum_{i}\left[\sum_{j} \frac{\rho\left(\theta_{j}, \varphi_{j}, \phi_{j}, \lambda\right)-K_{i}\left(\theta_{j}, \varphi_{j}, \phi_{j}\right)}{\omega_{j}(\lambda)} \times\left(\sum_{l} \frac{K_{i}\left(\theta_{l}, \varphi_{l}, \phi_{l}\right)-K_{k}\left(\theta_{l}, \varphi_{l}, \phi_{l}\right)}{\omega_{l}(\lambda)}\right)^{-1}\right]
\end{gathered}
$$

where $\omega_{l}(\lambda)$ is a weight given to each observation, and $d$ is the degrees of freedom that is number of observations minus number of parameters, $f_{k}$.

\subsubsection{Warren Model}

Reflectance was measured as 600, 660, and $900 \mathrm{~nm}$ from a $22 \mathrm{~m}$ tower, at South Pole Station, in Warren et al. [18]. The SZA varied from $67^{\circ}$ to $89.3^{\circ}$ over the full range of VZA, azimuth angle between Sun and view, and azimuth angle between Sun and sastrugi. Measurements were made with $15^{\circ}$ field of view at $15^{\circ}$ intervals in VZA and azimuth angle between Sun and view. They analyzed the variation of BRDF measurements with solar elevation angle, wavelength, sastrugi azimuth, models of sastrugi reflectance, forward peak and near-nadir views. Furthermore, an anisotropic reflectance pattern was developed by using a three-term Fourier series in azimuth angle between Sun and view:

$$
\begin{gathered}
R\left(\mu_{0}, \mu_{r}, \phi\right)=c_{1}+c_{2} \cos (\pi-\phi)+c_{3} \cos [2(\pi-\phi)] \\
c_{1}=\mathrm{a}_{0}+\mathrm{a}_{1}\left(1-\mu_{r}\right) \\
c_{2}=\mathrm{a}_{2}\left(1-\mu_{r}\right) \\
c_{3}=\mathrm{a}_{3}\left(1-\mu_{r}\right) \\
\mathrm{a}_{j}=\mathrm{b}_{0 \mathrm{j}}+\mathrm{b}_{1 \mathrm{j}} \mu_{0}+\mathrm{b}_{2 \mathrm{j}} \mu_{0}^{2}
\end{gathered}
$$

where $\mu_{0}=\cos \theta, \mu_{r}=\cos \varphi$. Thus, a total of 12 coefficients needed are determined by a least-squares-fitting method.

\subsubsection{Hudson Model}

Hudson et al. [19] extended the measurements of Warren et al. [18] with a wider range of SZAs $\left(51^{\circ}-87^{\circ}\right)$ and a broader spectrum range, from 350 to $2400 \mathrm{~nm}$, at Dome C. In Hudson et al. [8], they used $71 \times 25=1775$ different patterns with observations made at 71 different SZAs and 25 different wavelengths $(350,375,400,425,450,475,500$, $525,550,575,600,625,650,675,700,725,750,775,800,825,850,875,900,925$, and 950 $\mathrm{nm}$ ), to develop parameterizations. Each pattern is composed of values of reflectance 
gridded at 288 angular locations (six VZAs and 48 relative solar azimuth angles). The data were divided into six different groups (Table 1 in Hudson et al. [19]), based on different spectral region and SZAs. Each group has different equations and scaling factors (Table 2 in Hudson et al. [19]), to perform with EOFs in Equation (9):

$$
R=1+U \Sigma V^{T}
$$

where $R$ is a $288 \times 1$ matrix, 1 is a $288 \times 1$ matrix of ones, $U$ is a $288 \times 2$ matrix gridded at 288 angular locations, $\Sigma$ is a $2 \times 2$ diagonal matrix with positive scale factors in decreasing order, and $V$ is a $1 \times 2$ matrix, [v1 v2]. In this paper, the first group in Table 1 and its corresponding equations and scaling factors in Table 2 of Hudson et al. [19] were used by considering the spectral region of DNB (500-900 nm) and region of LZA.

\subsection{Lunar Irradiance Model}

Miller-Turner 2009 (MT2009) is a TOA lunar spectral irradiance model. It was developed for calibrating nighttime low-light measurements from VIIRS DNB, to achieve quantitative nighttime multispectral applications [34]. This model was based on the solar source observations, lunar spectral albedo data, time-varying Sun/Earth/Moon distances, and lunar phase angle (LPA). If users input a specific date and time, the model is able to output the corresponding $1 \mathrm{~nm}$ resolution lunar irradiance, in the range of 0.2 to $2.8 \mu \mathrm{m}$. Figure 2 shows five spectral irradiance curves from MT2009, changing with LPA, in 2019. All the five lunar spectral irradiances are around 14:30 in May 2019. They have a similar trend with the wavelength on the whole, but the specific irradiance value is obviously different at different LPAs.

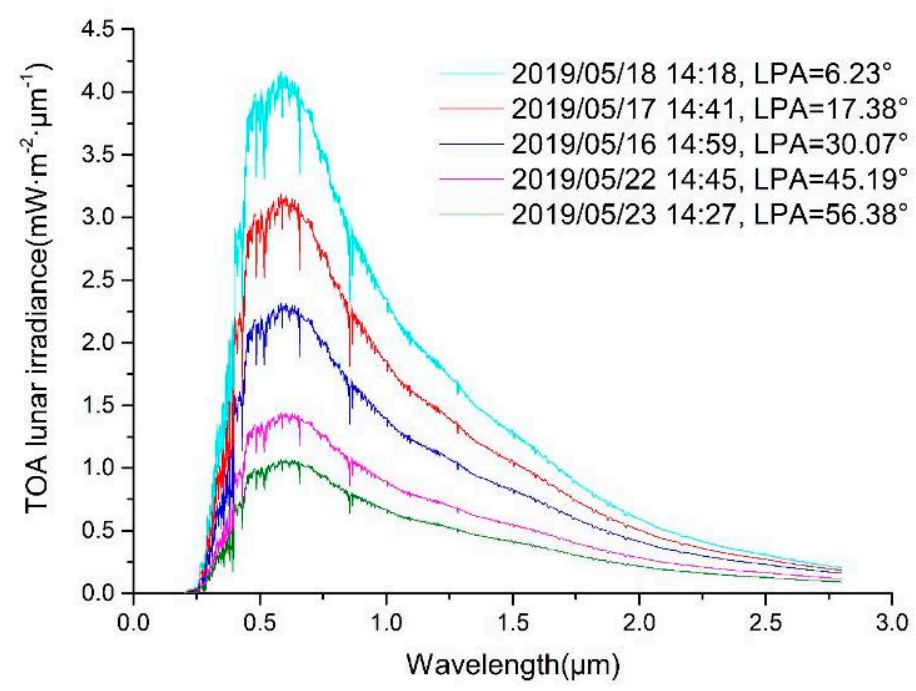

Figure 2. Top-of-atmosphere (TOA) lunar spectral irradiance from MT2009, under five different lunar phase angles (LPAs), in 2019.

\section{Methodology and Study Area}

In this study, first of all, the S-NPP VIIRS DNB observations and MT2009 lunar irradiance model were used to calculate the TOA nighttime reflectance of Dome C during 2012 to 2020. Second, the systematical analyses of angles' influence on the nighttime TOA reflectance were conducted, including the LZA, VZA, and relative lunar azimuth angle (RAA). Third, three BRDF models (RossLi BRDF model, Warren model, and Hudson model) are respectively applied, to explore their applicability to describe the nighttime TOA of Dome C. 


\subsection{Study Area}

The study area is in the Antarctic Dome C site $\left(75.1^{\circ} \mathrm{S}, 123.4^{\circ} \mathrm{E}\right.$, elevation $\left.3.2 \mathrm{~km}\right)$. Figure 3 shows the location of Dome $C$ in the southern hemisphere. This site is extremely cold (temperature down to $-84^{\circ} \mathrm{C}$ ), is covered with uniform and flat permanent snow, is cloudless most of the time, and has very high atmospheric stability due to low water vapor content, low aerosol content, and low wind speed [16]. Thus, it has been widely used in satellite sensor calibration and validation $[13,16-18,29,35-46]$. What is more, Dome $C$ is located in a high latitude area near the South Pole, so polar orbiting satellites overpass this site more frequently, and the special phenomenon of polar daytime and polar night provides a clear distinction between day and night. Moreover, there is a large diurnal variation in reflectance due to bidirectional effects [45] that is also helpful to study the impact of related angles on reflectance.

\subsection{Selection of Observations}

The criteria to select the S-NPP VIIRS DNB data are summarized as follows:

(1) The study area is a circular area centered at $75.1^{\circ} \mathrm{S}, 123.4^{\circ} \mathrm{E}$, with a $10 \mathrm{~km}$ radius. Moreover, cloud-contaminated data are removed according to the spatial uniformity (ratio of 1 standard deviation to mean reflectance over the study area) with a threshold value of $5 \%$ [44-46].

(2) LPA is less than $90^{\circ}$ to ensure sufficient moonlight.

(3) LZA is less than $75^{\circ}$ to ensure sufficient moonlight, too.

(4) SZA is greater than $118.4^{\circ}$, to remove the influences of stray-light effects present at Dome C, during the observations [21].

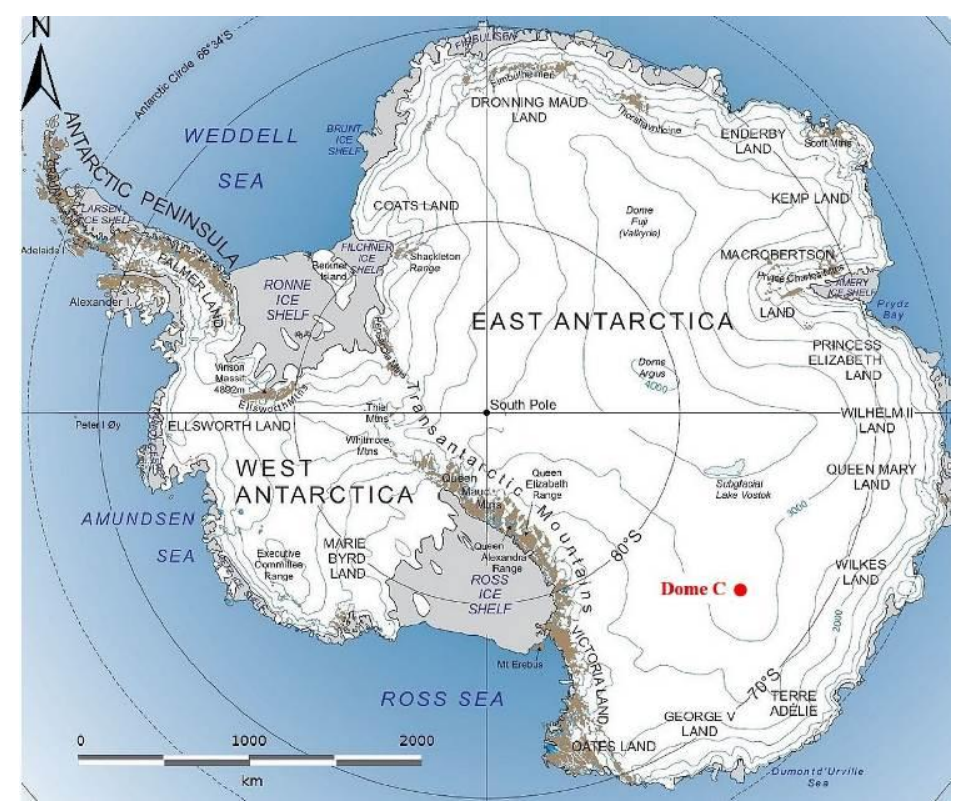

Figure 3. The location of Dome C site in the southern hemisphere.

Under the above restrictions, every selected day includes 1-4 cases. In conclusion, there are 90 cases in 2012, 82 in 2013, 97 in 2014, 100 in 2015, 95 in 2016, 119 in 2017, 123 in 2018, 122 in 2019, and 124 in 2020. There was a total of 952 cases in the nine years from 2012 to 2020. Moreover, all of these nighttime DNB observations are between April and August every year, and the data nearly covering the sensor's whole lifetime were collected from the NOAA's Comprehensive Large Array-Data Stewardship System. Figure 4 shows four observations of S-NPP VIIRS DNB over Dome C, under moonlight, on 16 June, and 20, 16 and 23 May 2019. The LPAs are $10.07^{\circ}, 21.21^{\circ}, 30.07^{\circ}$, and $56.38^{\circ}$, respectively. It is obvious that the images become darker and the value of the radiance becomes smaller with the 
increase of LPAs. The red "+" marks the center of the site used in this study. Furthermore, more details are listed in Table 3.

\subsection{Further Data Filtering According to LPA}

There are the scatter plots of our calculated nighttime TOA reflectance and LPA with uniform axes during 2012-2020 in Figure 5. It is found that the relationship is a ' $\sqrt{ }$ ' distribution under the primary selection criteria $\left(\mathrm{LPA}<90^{\circ}, \mathrm{LZA}<75^{\circ}, \mathrm{SZA}>118.4^{\circ}\right.$ ). There is a sharply decreasing tendency when the LPA is less than $15^{\circ}$, and a relative increasing tendency when the LPA is greater than $15^{\circ}$. However, the phenomenon is the least obvious in 2013, and this should be related to the SRF change of S-NPP VIIRS DNB between April and May 2013, due to mirror degradation [47]. Moreover, the points whose reflectance values are extremely high mainly gather on both sides of each graph. On the left side of each graph, where the LPA is less than $5^{\circ}$ or so, the extremely high reflectance should have a close relationship with the opposition effects of the moon $[6,34,48]$. On the right side, where the LPA is greater than $70^{\circ}$ or so, the signal-to-noise ratio (SNR) of VIIRS DNB HGS may decrease under low moonlight. Therefore, to cut down these bad effects, the LPA criterion was then changed to $5^{\circ}-70^{\circ}$. This change significantly cut down the unexpected reflectance on both sides, especially in 2019, and then the reflectance turned to be relatively uniformly distributed with LPA. In addition, a deficiency with the MT2009 model also exits. If the lunar model can be able to account for the lunar opposition surge and lower the minimum valid value of LPA, there will be less uncertainty and more data for subsequent analyses, pointing towards an improvement.
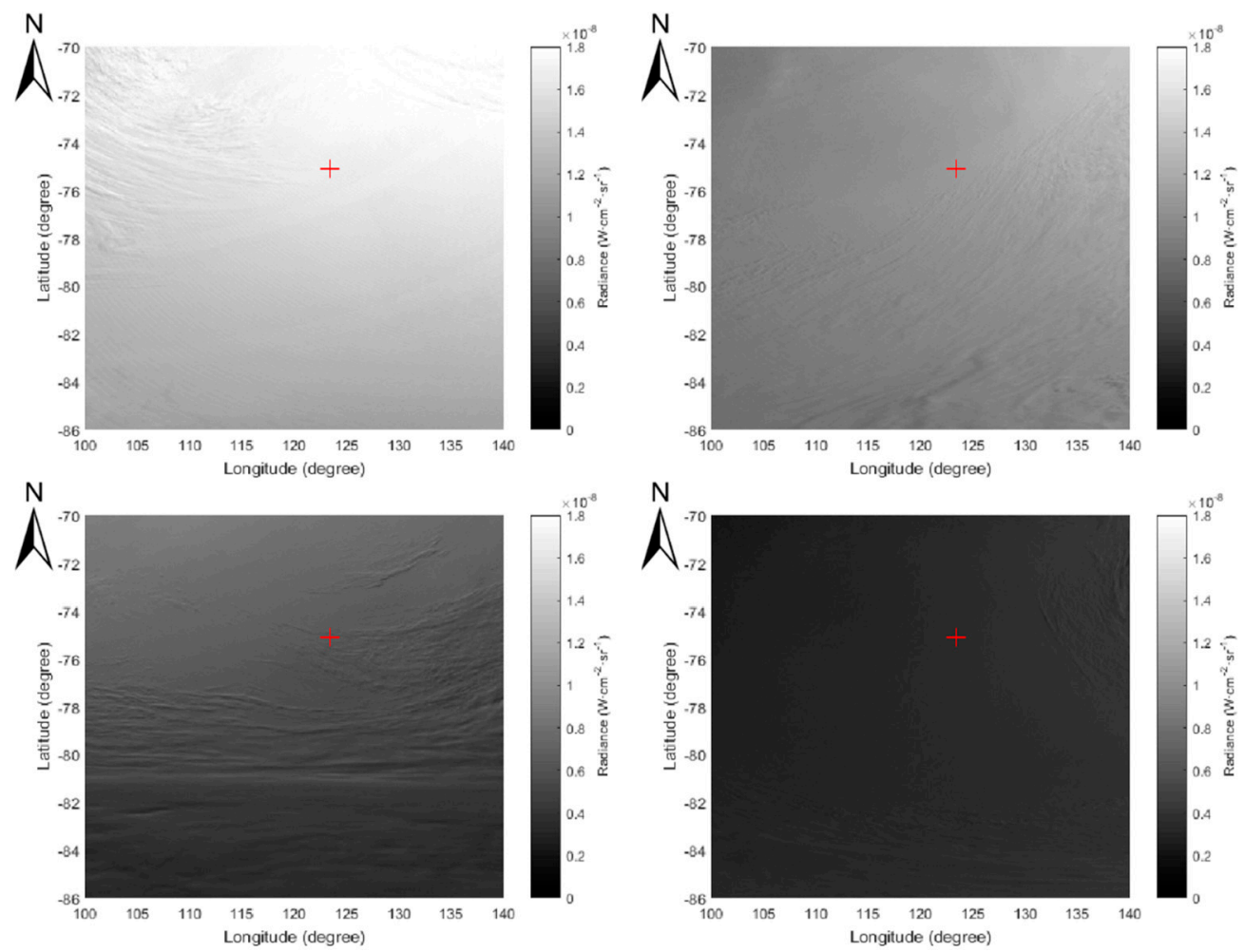

Figure 4. Four observations of Suomi National Polar-Orbiting Partnership (S-NPP) VIIRS DNB over Dome C, under moonlight, on 16 June and 20, 16 and 23 May 2019. The LPAs are $10.07^{\circ}, 21.21^{\circ}$, $30.07^{\circ}$, and $56.38^{\circ}$, respectively. Red " + " marks the center of the site used in this study. 
Table 3. Specific characteristics of these four observations in Figure 4.

\begin{tabular}{ccccccc}
\hline & $\begin{array}{c}\text { Day of } \\
\text { Year of } \\
\mathbf{2 0 1 9}\end{array}$ & $\begin{array}{c}\text { Universal } \\
\text { Time Co- } \\
\text { ordinated }\end{array}$ & LPA $\left(^{\circ}\right)$ & SZA $\left(^{\circ}\right.$ ) & LZA $\left(^{\circ}\right)$ & VZA $\left(^{\circ}\right)$ \\
\hline 1 & 167 & $13: 37$ & 10.07 & 125.59 & 57.26 & 26.43 \\
2 & 140 & $13: 43$ & 21.21 & 122.66 & 61.64 & 24.69 \\
3 & 136 & $14: 59$ & 30.07 & 123.72 & 71.21 & 4.14 \\
4 & 143 & $14: 27$ & 56.38 & 124.57 & 67.52 & 9.48 \\
\hline
\end{tabular}

LPA, lunar zenith angle; LZA, lunar zenith angle.

\subsection{Data Processing}

First, the nighttime TOA reflectance $R$ is calculated by the following formula:

$$
\begin{gathered}
R=1+U \Sigma V^{T} \\
R=L_{D N B} / L_{M T 2009}
\end{gathered}
$$

where $L_{D N B}$ is the observation radiance from VIIRS DNB, and $L_{M T 2009}$ is the TOA downwelling lunar radiance and is determined by the following:

$$
L_{M T 2009}=E_{m} \times \cos \left(\theta_{0}\right) / \pi
$$

where $\theta_{0}$ denotes LZA, $E_{m}$ is TOA down-welling lunar irradiance and output from MT2009 model. The following is the calculation equation of lunar irradiance:

$$
E_{m}=\frac{\int_{\lambda_{2}}^{\lambda_{1}} I_{M T}(\lambda) \operatorname{SRF}(\lambda) d \lambda}{\int_{\lambda_{2}}^{\lambda_{1}} \operatorname{SRF}(\lambda) d \lambda}
$$

where $S R F$ represents the spectral response function of $\mathrm{DNB}$, and $I_{M T}(\lambda)$ is the lunar irradiance spectra obtained from the MT2009 model for a specific date.

Second, there are three surface BRDF models, including RossLi BRDF, Warren and Hudson model. These BRDF models were respectively combined with nighttime various angles at Dome C, including LZA, VZA, and RAA, to simulate the nighttime radiance at satellite. Then the simulated radiance results are compared with the observed values to analyze the applicability of these models at night from 2012 to 2020. Figure 6 shows the flowchart of analyzing the applicability of three BRDF models at night. Moreover, the core calculation process of the BRDF models is in the black dotted box. To be specific, the coefficients of the RossLi BRDF model and Warren model were derived by using the least squares method based on the measurements data of Dome $C$, and the Hudson model was originally developed based on the same measurements data. Moreover, because the measurements were made at a $25 \mathrm{~nm}$ resolution, the average values of model coefficients from 500 to $900 \mathrm{~nm}$ were used to replace the coefficients of RossLi BRDF model and Warren model in DNB. Then the simulated reflectance can be calculated under arbitrary LZA, VZA, and RAA. For the Hudson model, it can only calculate the reflectance of $\mathrm{VZA}$ at $15^{\circ}$ resolution and relative azimuth at $7.5^{\circ}$ resolution under a given LZA and wavelength. Therefore, at first, the wavelength was set at $1 \mathrm{~nm}$ resolution from 500 to $900 \mathrm{~nm}$. Then the reflectance $R_{s}(\lambda)$ was interpolated over VZA and relative azimuth, using the Bicubic interpolation method. Finally, the modeled reflectance, $R$, of DNB is obtained by convoluting $R_{S}(\lambda)$ with S-NPP DNB $S R F(\lambda)$ :

$$
R=\frac{\int_{\lambda_{2}}^{\lambda_{1}} R_{S}(\lambda) \operatorname{SRF}(\lambda) d \lambda}{\int_{\lambda_{2}}^{\lambda_{1}} \operatorname{SRF}(\lambda) d \lambda}
$$




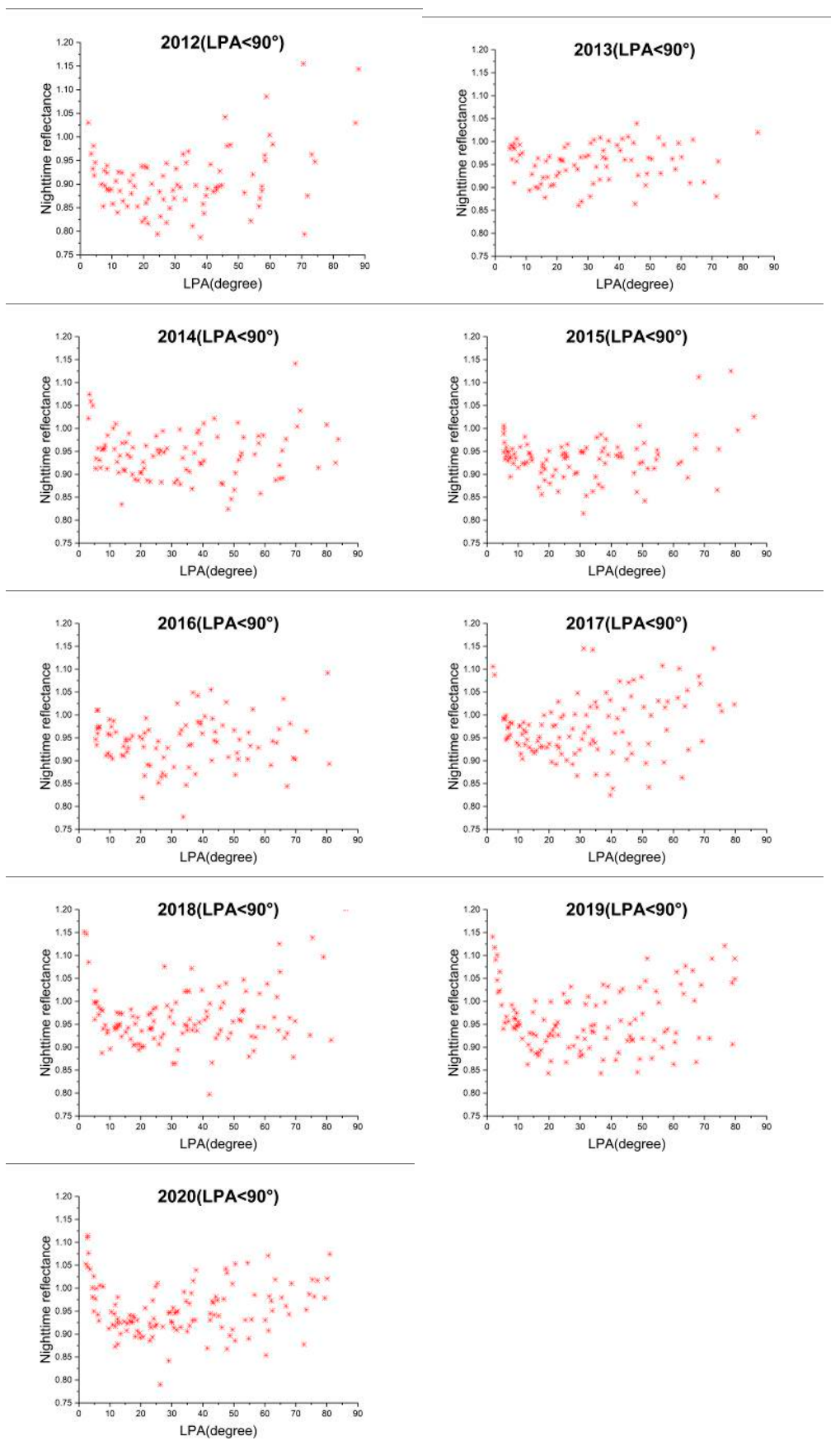

Figure 5. The relationship between nighttime TOA reflectance and LPA, with unified axes under primary selection criteria during 2012-2020 (LPA $<90^{\circ}, \mathrm{LZA}<75^{\circ}$, and SZA $\left.>118.4^{\circ}\right)$. 


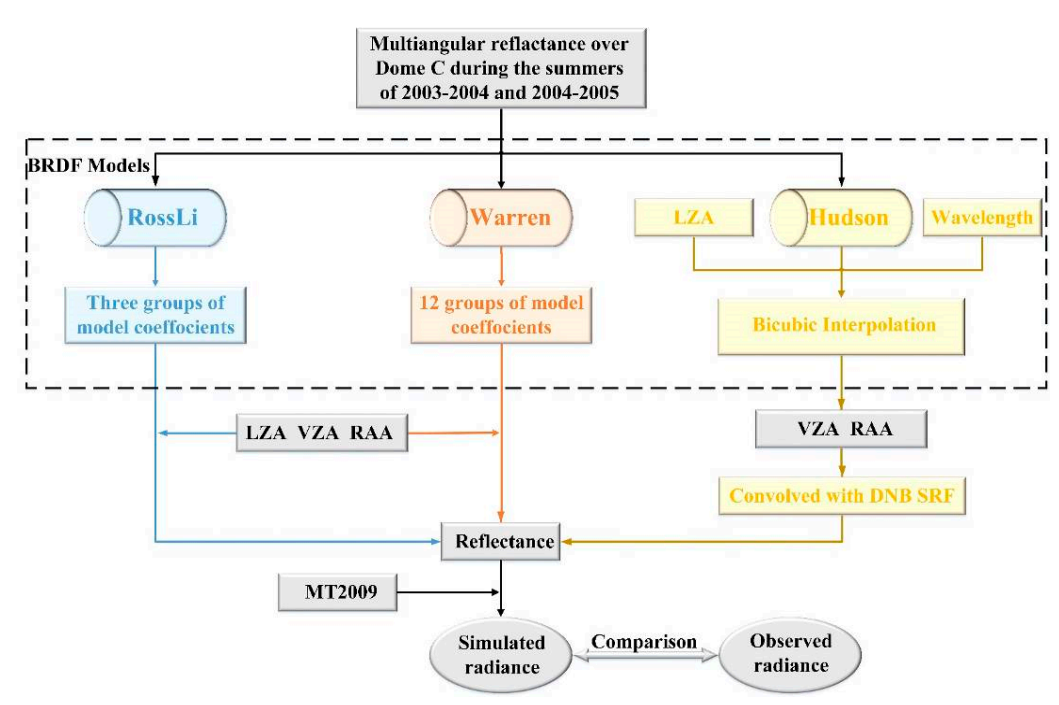

Figure 6. The flowchart of analyzing the applicability of three bidirectional reflectance distribution functions (BRDF) models at night. The core calculation process of the BRDF models is in the black dotted box.

In this study, the use of same measurements data theoretically unified the three BRDF models. However, there were still some different errors in the application of these models. For RossLi BRDF model and Warren model, using the average values of model coefficients from 500 to $900, \mathrm{~nm}$ to replace the DNB coefficients brought an error. Figure 7 shows the model coefficients of RossLi BRDF model and Warren model varying with wavelength, respectively. The variances of the three scattering coefficients of the RossLi BRDF model are $0.0017,0.0125$, and 0.0042 , respectively, and the variances of the Warren model coefficients are between 0.0936 and 1.1971. Thus, their fluctuation with wavelength is very small, and the errors of the averaging process are small and limitation. For the Hudson model, it can only calculate the reflectance under the VZA at $15^{\circ}$ resolution and relative azimuth at $7.5^{\circ}$ resolution. Because the resolutions are relatively low, the Bicubic interpolation method was used in the calculation, and this processing may add some errors to results.
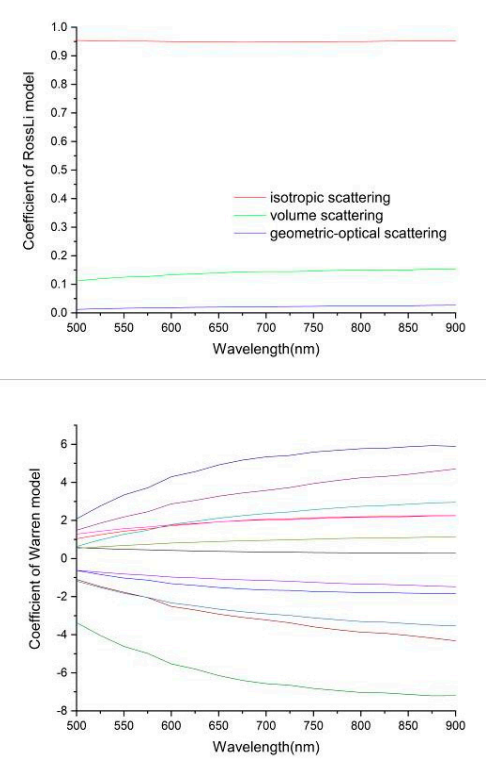

Figure 7. Model coefficients of RossThick-LiSparseReciprocal (RossLi) BRDF model and Warren model varying with wavelength, respectively. 


\section{Results and Discussion}

\subsection{The Impact of Multiple Angles on Nighttime TOA Reflectance}

The angular analysis is divided into three parts: VZA, LZA, and RAA.

\subsubsection{Impact of VZA on Nighttime TOA Reflectance}

The range of the LZA is approximately between $50^{\circ}$ and $75^{\circ}$ due to the geographical location of Dome $\mathrm{C}$ under the selection criteria $\left(5^{\circ}<\mathrm{LPA}<70^{\circ}\right.$, $\mathrm{LZA}<75^{\circ}$, and SZA $>$ $118.4^{\circ}$ ). Specifically, the LZA is between $55^{\circ}$ and $75^{\circ}$ from 2012 to 2018 , and between $50^{\circ}$ and $75^{\circ}$ from 2019 to 2020 . The range of the VZA depending on the sensor design is approximately between $0^{\circ}$ and $70^{\circ}$. Moreover, the viewing azimuth angle (VAA) is always between 0 and 360 degrees. The RAA approximately ranges from 0 to 180 degrees during 2012-2020. Considering the relatively even distribution of reflectance with LZA, the nighttime TOA reflectance data were divided into five groups, with $5^{\circ}$ increments of LZA $\left(50^{\circ}-55^{\circ}, 55^{\circ}-60^{\circ}, 60^{\circ}-65^{\circ}, 65^{\circ}-70^{\circ}\right.$, and $\left.70^{\circ}-75^{\circ}\right)$. Furthermore, the LZA was regarded as a constant in each group.

Figure 8 shows the distribution of nighttime TOA reflectance of the five groups in nine years (2012-2020) over Dome $C$ in the viewing hemisphere. The radius of every circle represents VZA with $10^{\circ}$ increments, and the polar angle of every circle represents S-NPP VAA with $30^{\circ}$ increments. The first column in Figure 8(a1-a5) are the scatter diagrams which can reflect the spatial distribution of the viewing geometry and the specific value of reflectance of each observation. The second column (b1-b5) plots the average reflectance in the corresponding VZA and VAA. It is evident that VAA is always between $120^{\circ}$ and $330^{\circ}$, so the viewing geometry is stable when S-NPP overpasses Dome C. When LZA is less than $65^{\circ}$ and VZA is less than $40^{\circ}$, the reflectance increases with the increase of VZA. Moreover, when LZA is less than $65^{\circ}$ and VZA is greater than $40^{\circ}$, the reflectance decreases with the increase of VZA. When LZA is greater than $65^{\circ}$, the reflectance has a tendency to increase with the increase of VZA.

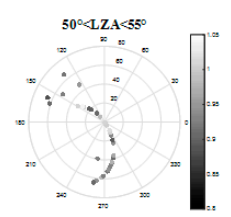

(a1)

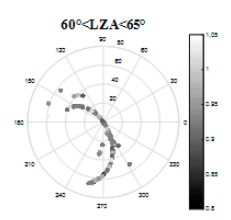

(a3)

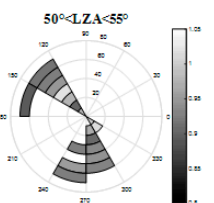

(b1)

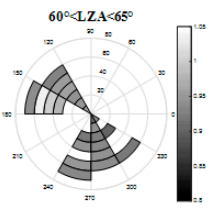

(b3)

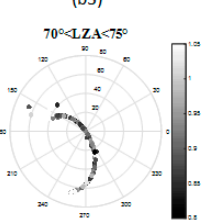

(a5)

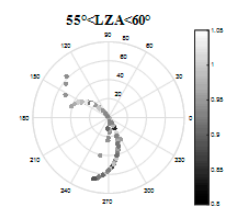

(a2)

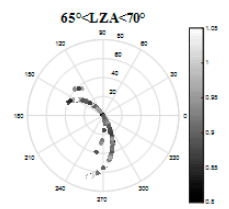

(a4)

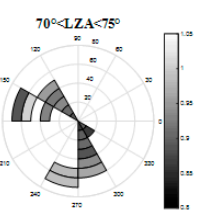

(b5)

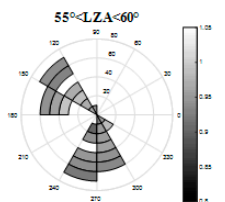

(b2)

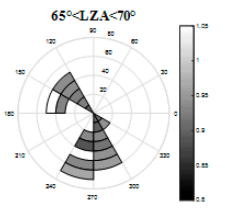

(b4)

Figure 8. The distribution of nighttime TOA reflectance in nine years (2012-2020) over Dome $C$ in the viewing hemisphere. The five rows are at LZAs between $50^{\circ}$ and $55^{\circ}$ $(\mathbf{a} 1, \mathbf{b} 1)$, between $55^{\circ}$ and $60^{\circ}(\mathbf{a} 2, \mathbf{b 2})$, between $60^{\circ}$ and $65^{\circ}(\mathbf{a} 3, \mathbf{b} 3)$, between $65^{\circ}$ and $70^{\circ}$ $(\mathbf{a} 4, \mathbf{b} 4)$, and between $70^{\circ}$ and $75^{\circ}(\mathbf{a} 5, \mathbf{b 5})$, respectively. The radius of every circle represents VZA with $10^{\circ}$ increments, and the polar angle represents S-NPP viewing azimuth angle (VAA) with $30^{\circ}$ increments. 
In addition, because the reflectance varies with both zenith angles (LZA and VZA), the variable-controlling approach was used to respectively analyze them. In each group they were divided into six cases, with $30^{\circ}$ increments, according to the RAA $\left(0^{\circ}-30^{\circ}, 30^{\circ}-\right.$ $60^{\circ}, 60^{\circ}-90^{\circ}, 90^{\circ}-120^{\circ}, 120^{\circ}-150^{\circ}$, and $150^{\circ}-180^{\circ}$ ). In each case, the LZA and RAA were regarded as constants so as to analyze the relationship between reflectance and VZA in nine years. The results are shown in Figures 9-13, where the red line in each diagram denotes the result of linear fitting. When LZA is between $50^{\circ}$ and $55^{\circ}$, there is only one case when RAA is in $0^{\circ}-30^{\circ}$ and $150^{\circ}-180^{\circ}$, respectively. Thus, there are no corresponding results on that conditions.

Figure 14 shows the slope and correlation coefficient $\left(R^{2}\right)$ of linear fitting of the previous 28 graphs Figures 9-13. These values are in the same order as the graphs in Figures 9-13, and the dotted black lines divide the results into the five groups. The following conclusions can be drawn.

(1) When LZA is less than $65^{\circ}$, especially when the RAA approaches $90^{\circ}$, the reflectance tends to decrease with the increase of VZA, which is consistent with the finding in Shao et al. [47] and Qiu et al. [49]. At $55^{\circ}-60^{\circ}$ of the LZA, the average of the slopes of linear fitting is the smallest, which means that the reflectance is relatively the most stable and little affected by the VZA.

(2) When LZA is higher than $65^{\circ}$, the reflectance increases with the increase of VZA. Generally, the variation is more sharply at $70^{\circ}-75^{\circ}$, so the effect of VZA reaches the most.

(3) In each group divided by LZA, the value of the slope tends to decrease at first and drops to the minimum when the RAA approaches $90^{\circ}$. It then increases with the increase of RAA. Besides, the maximum slope in each group always corresponds to the maximum RAA.
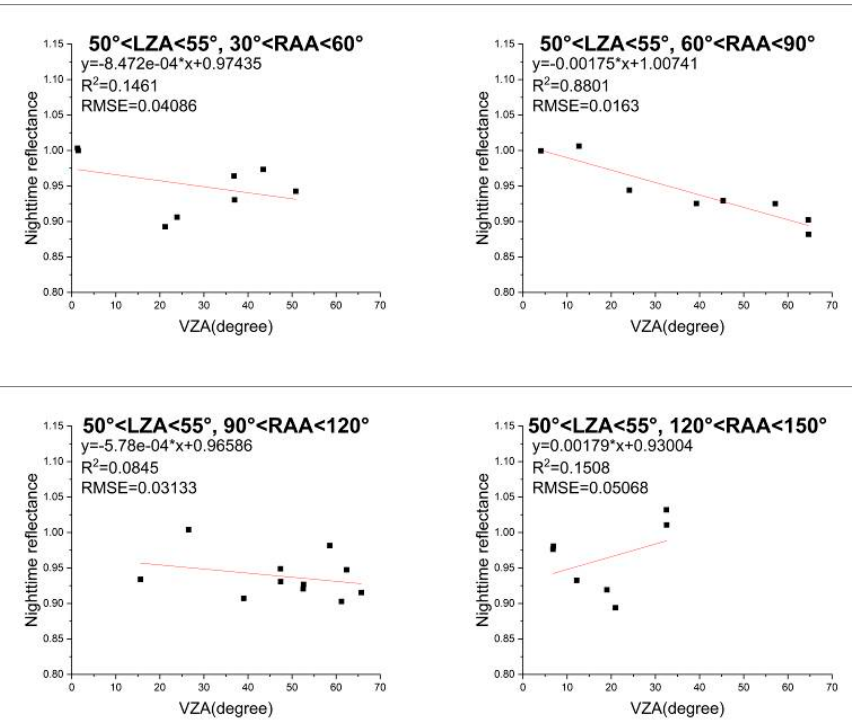

Figure 9. The relationship between nighttime TOA reflectance and VZA, in nine years, under the selection criteria $\left(50^{\circ}<\mathrm{LZA}<55^{\circ}, 5^{\circ}<\mathrm{LPA}<70^{\circ}\right.$, and SZA $\left.>118.4^{\circ}\right)$. The red line denotes the result of linear fitting. 

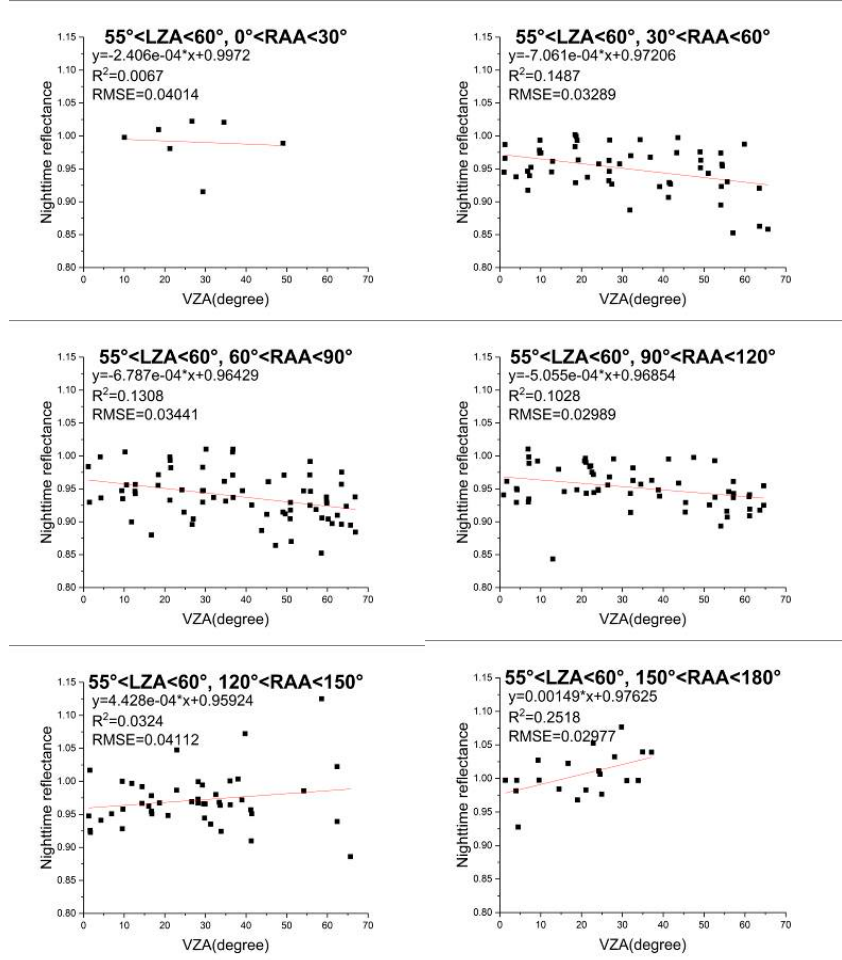

Figure 10. The relationship between nighttime TOA reflectance and VZA, in nine years, under the selection criteria $\left(55^{\circ}<\mathrm{LZA}<60^{\circ}, 5^{\circ}<\mathrm{LPA}<70^{\circ}\right.$, and SZA $\left.>118.4^{\circ}\right)$. The red line denotes the result of linear fitting.
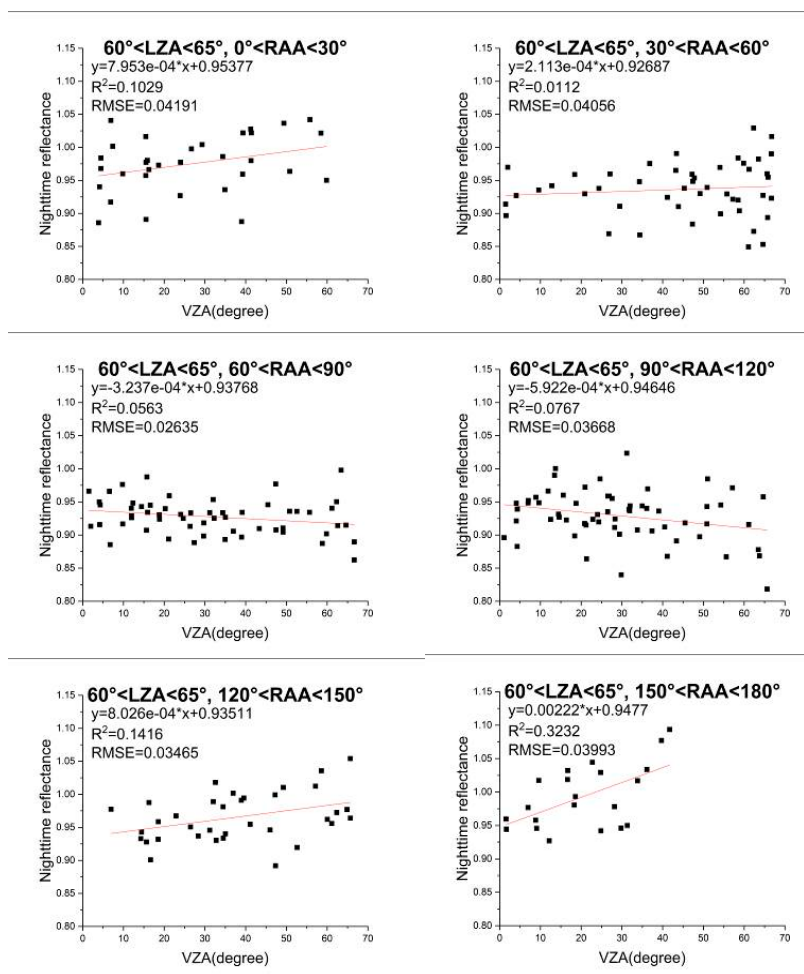

Figure 11. The relationship between nighttime TOA reflectance and VZA, in nine years, under the selection criteria $\left(60^{\circ}<\mathrm{LZA}<65^{\circ}, 5^{\circ}<\mathrm{LPA}<70^{\circ}\right.$, and SZA $\left.>118.4^{\circ}\right)$. The red line denotes the result of linear fitting. 

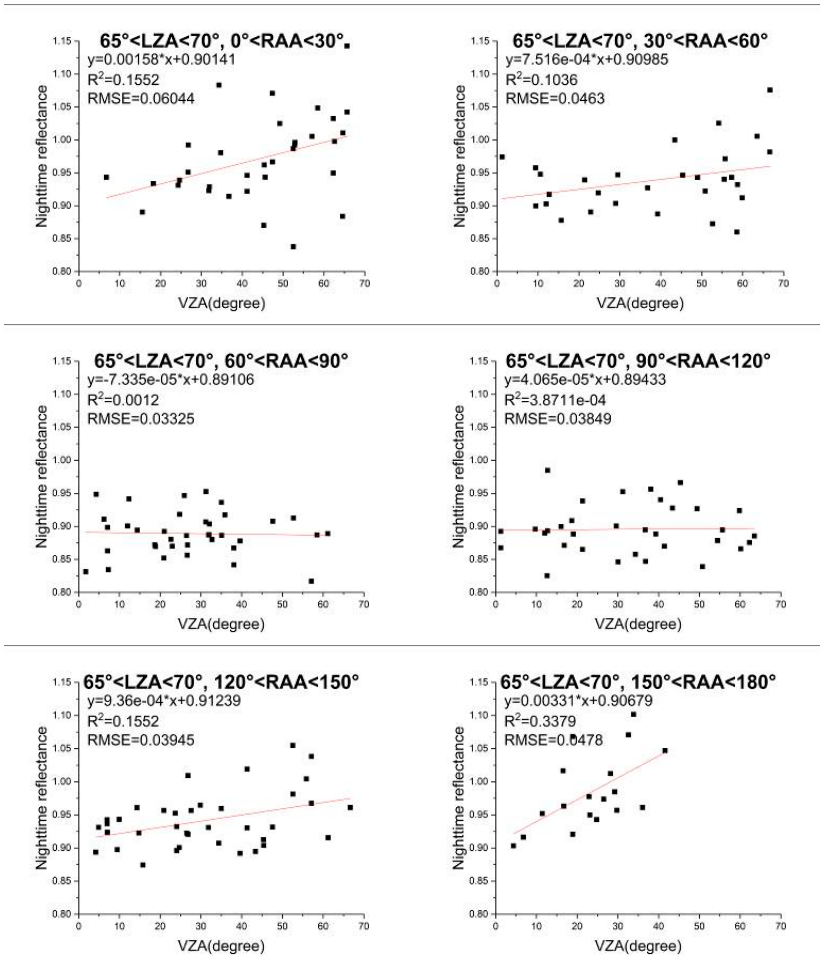

Figure 12. The relationship between nighttime TOA reflectance and VZA, in nine years, under the selection criteria $\left(65^{\circ}<\mathrm{LZA}<70^{\circ}, 5^{\circ}<\mathrm{LPA}<70^{\circ}\right.$, and SZA $\left.>118.4^{\circ}\right)$. The red line denotes the result of linear fitting.
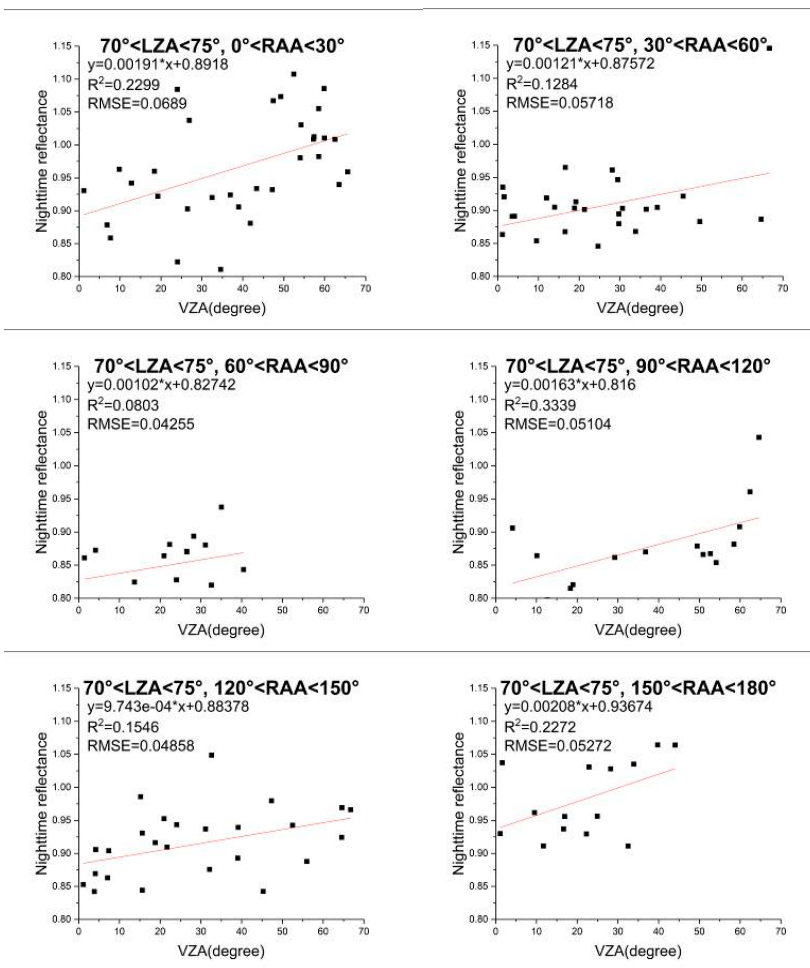

Figure 13. The relationship between nighttime TOA reflectance and VZA, in nine years, under the selection criteria $\left(70^{\circ}<\mathrm{LZA}<75^{\circ}, 5^{\circ}<\mathrm{LPA}<70^{\circ}\right.$, and SZA $\left.>118.4^{\circ}\right)$. The red line denotes the result of linear fitting. 


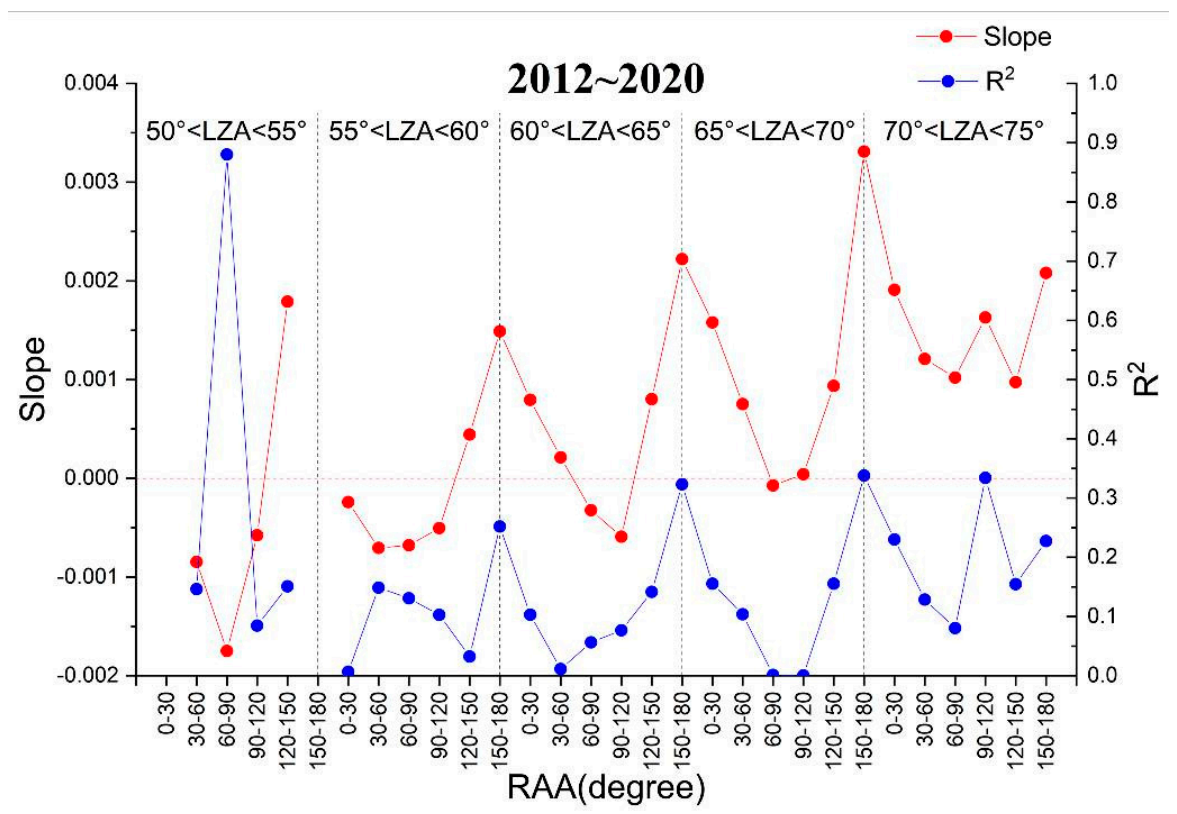

Figure 14. The slope and correlation coefficient $\left(R^{2}\right)$ of linear fitting of the previous 28 graphs (Figures 9-13). These values are in the same order as the graphs in Figures 9-13. The dotted black lines divide the results into the five groups.

\subsubsection{Impact of LZA on Nighttime TOA Reflectance}

Based on the variable-controlling approach, the nighttime TOA reflectance data from 2012 to 2020 were divided into seven groups, with $10^{\circ}$ increments of VZA $\left(0^{\circ}-10^{\circ}, 10^{\circ}-20^{\circ}\right.$, $20^{\circ}-30^{\circ}, 30^{\circ}-40^{\circ}, 40^{\circ}-50^{\circ}, 50^{\circ}-60^{\circ}$, and $60^{\circ}-70^{\circ}$ ). In each group they were divided into six cases, with $30^{\circ}$ increments, according to the RAA $\left(0^{\circ}-30^{\circ}, 30^{\circ}-60^{\circ}, 60^{\circ}-90^{\circ}, 90^{\circ}-120^{\circ}\right.$, $120^{\circ}-150^{\circ}$, and $\left.150^{\circ}-180^{\circ}\right)$. In each case, the VZA and the RAA were regarded as constants, so as to analyze the relationship between reflectance and LZA. The results are shown in Figures 15 and 16, where the red line in each diagram denotes the result of linear fitting, as well as Table 4, including the ranges of VZA and RAA, linear fitting equations, correlation coefficient $\left(R^{2}\right)$, root-mean-square-error (RMSE), and the number of cases. When VZA is in $40^{\circ}-70^{\circ}$ and RAA is in $150^{\circ}-180^{\circ}$, there are no corresponding reflectance results. Figure 17 shows the slope and correlation coefficient $\left(R^{2}\right)$ of linear fitting of the previous 39 results in Figure 15, Figure 16 and Table 4, and the dotted black lines divide the results into the seven groups. The following conclusions can be drawn:

(1) Only when the VZA is in $50^{\circ}-60^{\circ}$ and RAA is less than $30^{\circ}$, and VZA is in $60^{\circ}-70^{\circ}$ and RAA is in $30^{\circ}-120^{\circ}$, the nighttime TOA reflectance is positively correlated with the LZA. In other cases, the reflectance is negatively correlated with the LZA.

(2) On the whole, as the absolute value of the slope decreases, the correlation coefficient tends to decrease. 

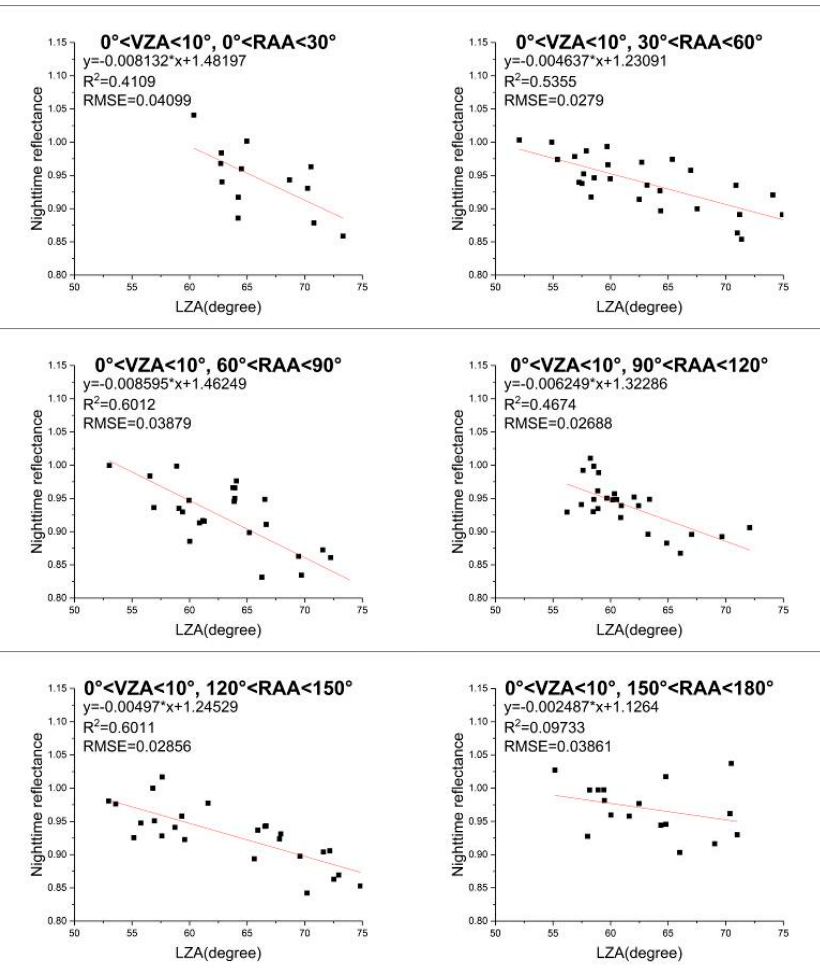

Figure 15. The relationship between nighttime TOA reflectance and LZA, in nine years, under the selection criteria $\left(0^{\circ}<\mathrm{VZA}<10^{\circ}, 5^{\circ}<\mathrm{LPA}<70^{\circ}\right.$, and $\left.\mathrm{SZA}>118.4^{\circ}\right)$. The red line denotes the result of linear fitting.
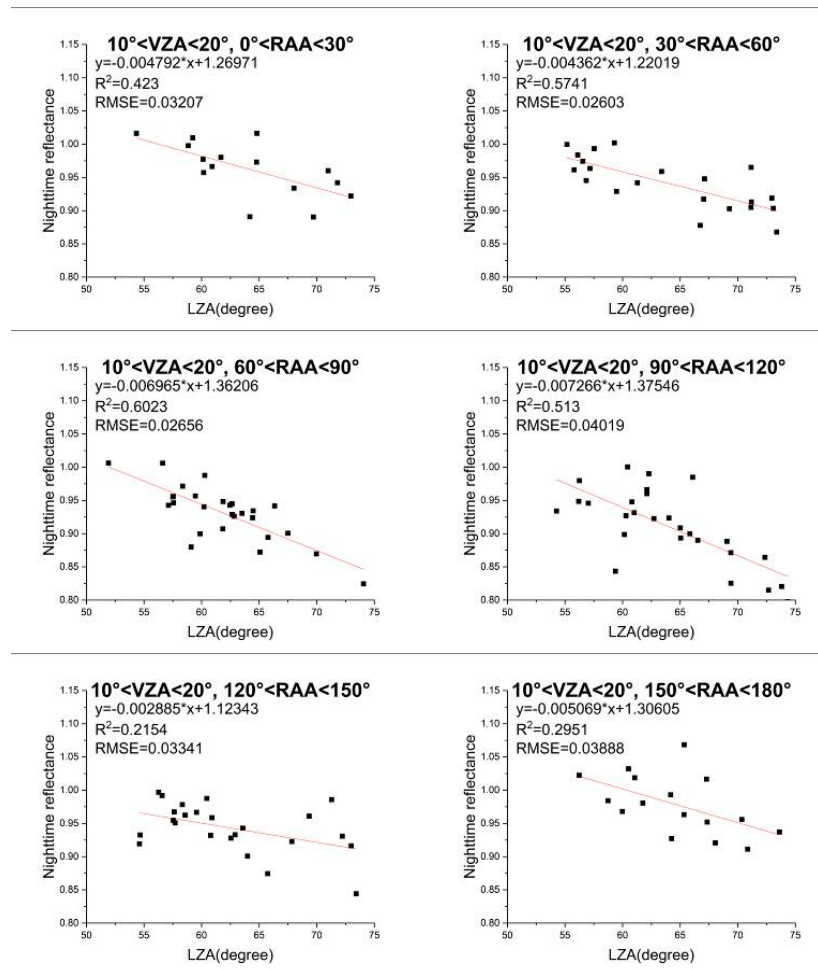

Figure 16. The relationship between nighttime TOA reflectance and LZA, in nine years, under the selection criteria $\left(10^{\circ}<\mathrm{VZA}<20^{\circ}, 5^{\circ}<\mathrm{LPA}<70^{\circ}\right.$, and SZA $\left.>118.4^{\circ}\right)$. The red line denotes the result of linear fitting. 


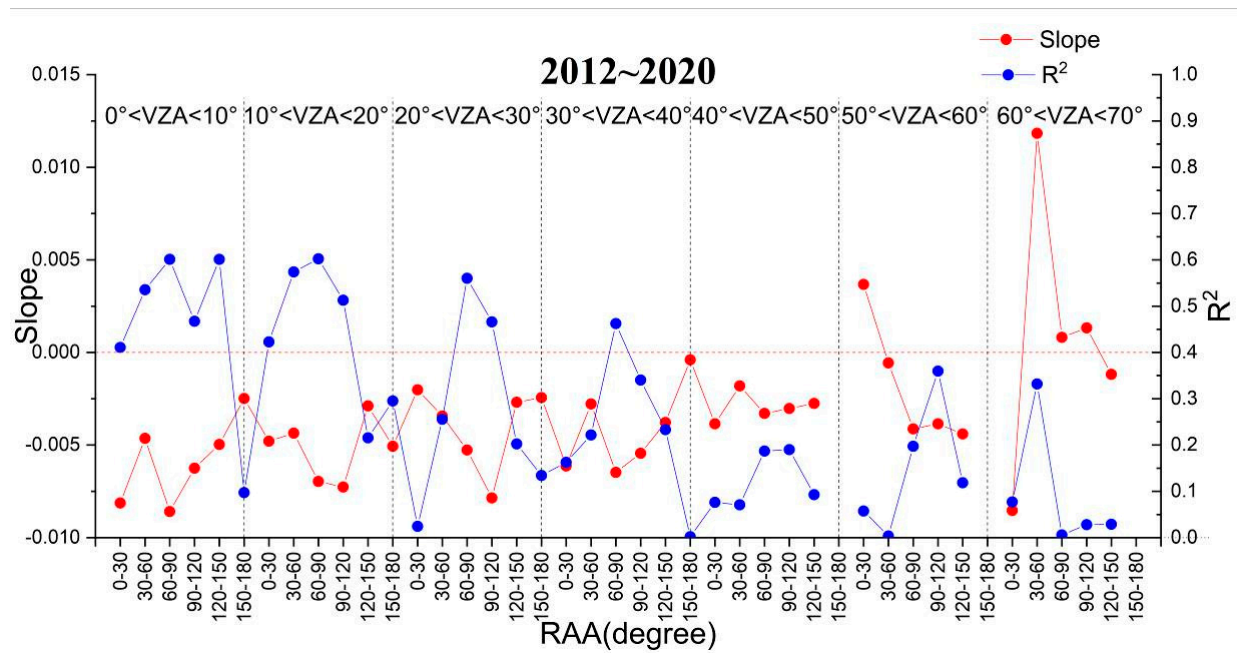

Figure 17. The slope and correlation coefficient $\left(\mathrm{R}^{2}\right)$ of linear fitting of the previous 39 results in Figure 15, Figure 16 and Table 4 . The dotted black lines divide the results into the seven groups.

\subsubsection{Impact of RAA on Nighttime TOA Reflectance}

Based on the variable-controlling approach, the nighttime TOA reflectance data from 2012 to 2020 were divided into five groups, with $5^{\circ}$ increments of LZA $\left(50^{\circ}-55^{\circ}, 55^{\circ}-60^{\circ}\right.$, $60^{\circ}-65^{\circ}, 65^{\circ}-70^{\circ}$, and $70^{\circ}-75^{\circ}$ ). In each group, they were divided into seven cases, with $10^{\circ}$ increments, according to the VZA $\left(0^{\circ}-10^{\circ}, 10^{\circ}-20^{\circ}, 20^{\circ}-30^{\circ}, 30^{\circ}-40^{\circ}, 40^{\circ}-50^{\circ}, 50^{\circ}-60^{\circ}\right.$, and $60^{\circ}-70^{\circ}$ ). In each case, the LZA and the VZA were regarded as constants, so as to analyze the relationship between nighttime TOA reflectance and RAA. The results are shown in Figures 18-21, where the red line in each diagram denotes the result of polynomial fitting.

In order to reduce the error caused by too little data, less than 10 corresponding cases were deleted. So when LZA is less than $55^{\circ}$ and VZA is in $0^{\circ}-70^{\circ}$, and LZA is in $70^{\circ}-75^{\circ}$ and VZA is in $60^{\circ}-70^{\circ}$, there are no corresponding reflectance results. Figure 22 shows the correlation coefficient $\left(\mathrm{R}^{2}\right)$ of polynomial fitting of the previous 27 graphs Figures 18-21. These values are in the same order as the graphs in Figures 18-21, and the dotted black lines divide the results into the four groups. The following conclusions can be drawn.

(1) In Figures 18-21, the nighttime reflectance decreases at first, and drops to the lowest when the RAA is about $90^{\circ}$, and then increases with the increase of RAA.

(2) The forward scattering $\left(\mathrm{RAA}=180^{\circ}\right)$ and backward scattering $\left(\mathrm{RAA}=0^{\circ}\right)$ are not symmetric at night, according to the distribution of reflectance with RAA.

(3) The fitting effect of quadratic polynomial on the relation between reflectance and RAA is relatively better. The correlation coefficient of the polynomial fitting is between 0.1129 and 0.8263 .

\subsection{Application of Three BRDF Model at Nighttime TOA}

The three angles (LZA, VZA, and RAA) have different effects on the nighttime reflectance, so it is necessary to look for a suitable nighttime TOA BRDF model of Dome $\mathrm{C}$ site. Figure 23 shows a comparison of the simulated nighttime radiance at satellite, respectively, using three models and the observed radiance during 2012-2020. Figure 24 shows the variation of the specific correlation coefficients and the RMSE between the simulated radiance and observed radiance over the years. The application of BRDF model at nighttime TOA can be indirectly illustrated by the correlation coefficient and RMSE. According to these results of the nine years, the following conclusions can be drawn.

(1) In Figure 23, the simulated nighttime radiance at satellite using BRDF models and the observed radiance agrees well. Almost all the results are located along the 1:1 line and show high consistency with a correlation coefficient of greater than 0.9723 and an RMSE of less than $0.0799 \mathrm{~W} \cdot \mathrm{cm}^{-2} \cdot \mathrm{sr}^{-1}$. 
(2) In Figure 23, the correlation of the simulated radiance and the observed has a decreasing tendency with the increase of radiance value, especially in the results of the RossLi BRDF model and Hudson model.

(3) The correlation coefficients, in descending order, each year, are Warren $>$ Hudson $>$ RossLi. The RMSEs, in ascending order, each year, are Warren $<$ Hudson $<$ RossLi. The reason why the applicability of RossLi BRDF model is lower than the other two models may be that the accuracy of RossLi BRDF model is reduced under a large zenith angle [23].

(4) During the nine years, as shown in Figure 24, the RossLi BRDF model and Hudson model have kept a good consistency. Thus, these two models may have similar effects in the description of the nighttime TOA over Dome C.

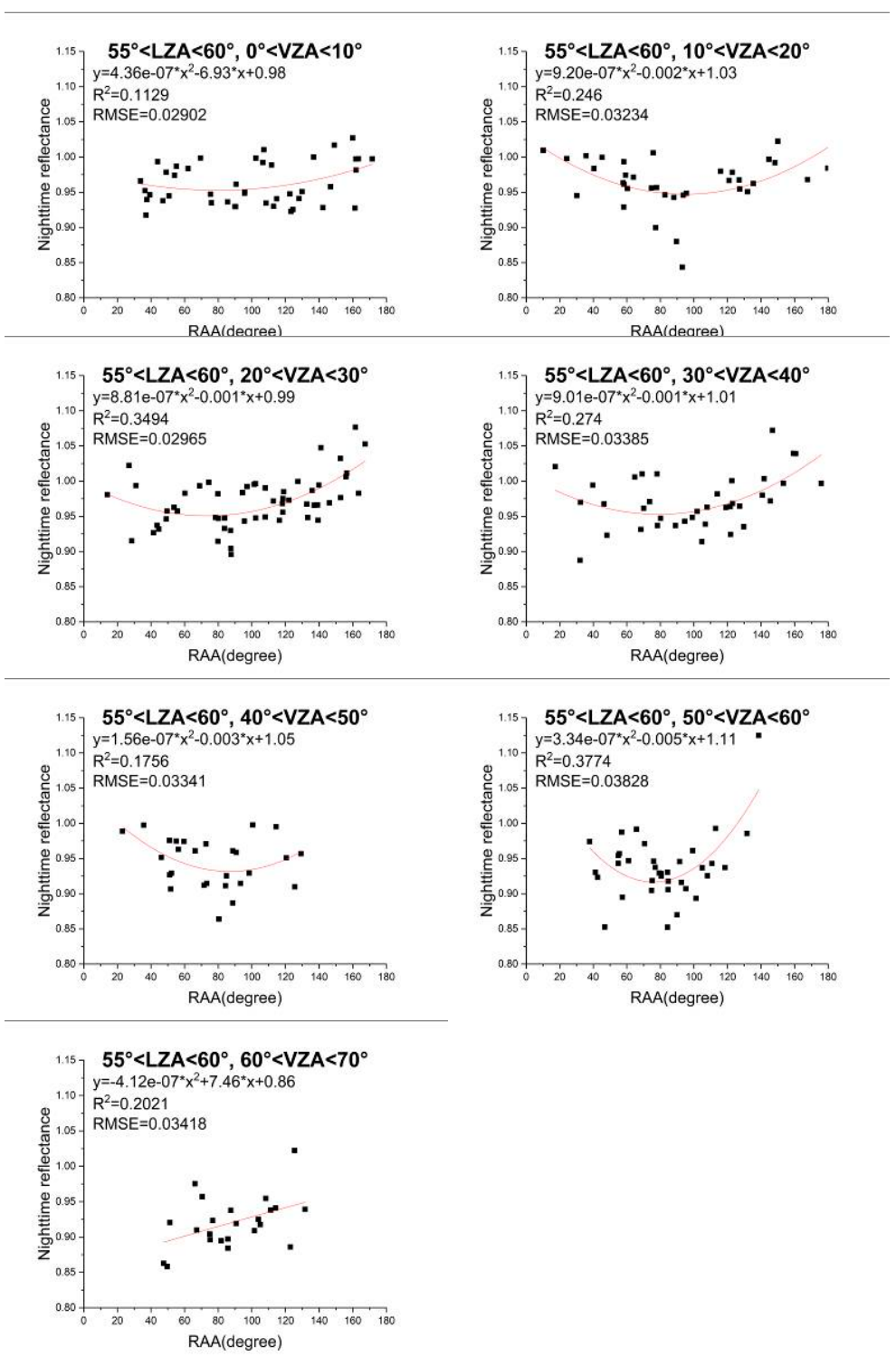

Figure 18. The relationship between nighttime TOA reflectance and RAA, in nine years, under the selection criteria $\left(55^{\circ}<\mathrm{LZA}<60^{\circ}, 5^{\circ}<\mathrm{LPA}<70^{\circ}\right.$, and SZA $\left.>118.4^{\circ}\right)$. The red line denotes the result of polynomial fitting. 


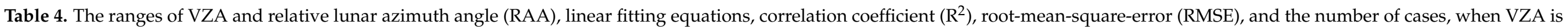
greater than 20 degrees.

\begin{tabular}{|c|c|c|c|c|c|}
\hline $\operatorname{VZA}\left({ }^{\circ}\right)$ & RAA $\left(^{\circ}\right)$ & Linear Fitting Equations & $\mathbf{R}^{2}$ & RMSE & Number of Cases \\
\hline \multirow[t]{5}{*}{$20-30$} & $0-30$ & $y=-0.002018 x+1.09869$ & 0.02447 & 0.06524 & 15 \\
\hline & $30-60$ & $y=-0.003435 x+1.14072$ & 0.2556 & 0.0372 & 27 \\
\hline & $60-90$ & $y=-0.005272 x+1.24841$ & 0.5602 & 0.02763 & 38 \\
\hline & $120-150$ & $y=-0.00269 x+1.12341$ & 0.2023 & 0.03174 & 28 \\
\hline & $150-180$ & $y=-0.002437 x+1.14849$ & 0.1342 & 0.03913 & 24 \\
\hline \multirow[t]{5}{*}{$30-40$} & 0-30 & $y=-0.006134 x+1.35817$ & 0.1625 & 0.06192 & 15 \\
\hline & $30-60$ & $y=-0.002781 x+1.1022$ & 0.2217 & 0.03659 & 16 \\
\hline & $90-120$ & $y=-0.005443 x+1.2702$ & 0.3403 & 0.03479 & 27 \\
\hline & $120-150$ & $y=-0.003783 x+1.20248$ & 0.2332 & 0.0414 & 31 \\
\hline & $150-180$ & $y=-0.0003982 x+1.04648$ & 0.001884 & 0.05543 & 14 \\
\hline \multirow[t]{5}{*}{$40-50$} & $0-30$ & $y=-0.003853 x+1.24236$ & 0.07624 & 0.06199 & 18 \\
\hline & $30-60$ & $y=-0.001811 x+1.05826$ & 0.07089 & 0.03142 & 25 \\
\hline & $60-90$ & $y=-0.003297 x+1.11836$ & 0.1869 & 0.03261 & 18 \\
\hline & $90-120$ & $y=-0.003026 x+1.1147$ & 0.1899 & 0.03529 & 18 \\
\hline & $120-150$ & $y=-0.002753 x+1.1167$ & 0.09274 & 0.04692 & 16 \\
\hline \multirow[t]{4}{*}{$50-60$} & $0-30$ & $y=-0.003675 x+0.75391$ & 0.05745 & 0.05679 & 19 \\
\hline & $60-90$ & $y=-0.004129 x+1.16262$ & 0.1973 & 0.03362 & 24 \\
\hline & $90-120$ & $y=-0.003857 x+1.15772$ & 0.3597 & 0.03325 & 28 \\
\hline & $120-150$ & $y=-0.004404 x+1.2833$ & 0.1185 & 0.06326 & 12 \\
\hline \multirow[t]{5}{*}{$60-70$} & $0-30$ & $y=-0.008533 x+1.5922$ & 0.07706 & 0.07173 & 10 \\
\hline & $30-60$ & $y=0.01183 x+0.19632$ & 0.3319 & 0.0657 & 21 \\
\hline & $60-90$ & $y=0.0008173 x+0.86726$ & 0.005966 & 0.03506 & 20 \\
\hline & $90-120$ & $y=0.001327 x+0.83565$ & 0.0281 & 0.04762 & 20 \\
\hline & $120-150$ & $y=-0.001188 x+1.03823$ & 0.02873 & 0.04263 & 14 \\
\hline
\end{tabular}



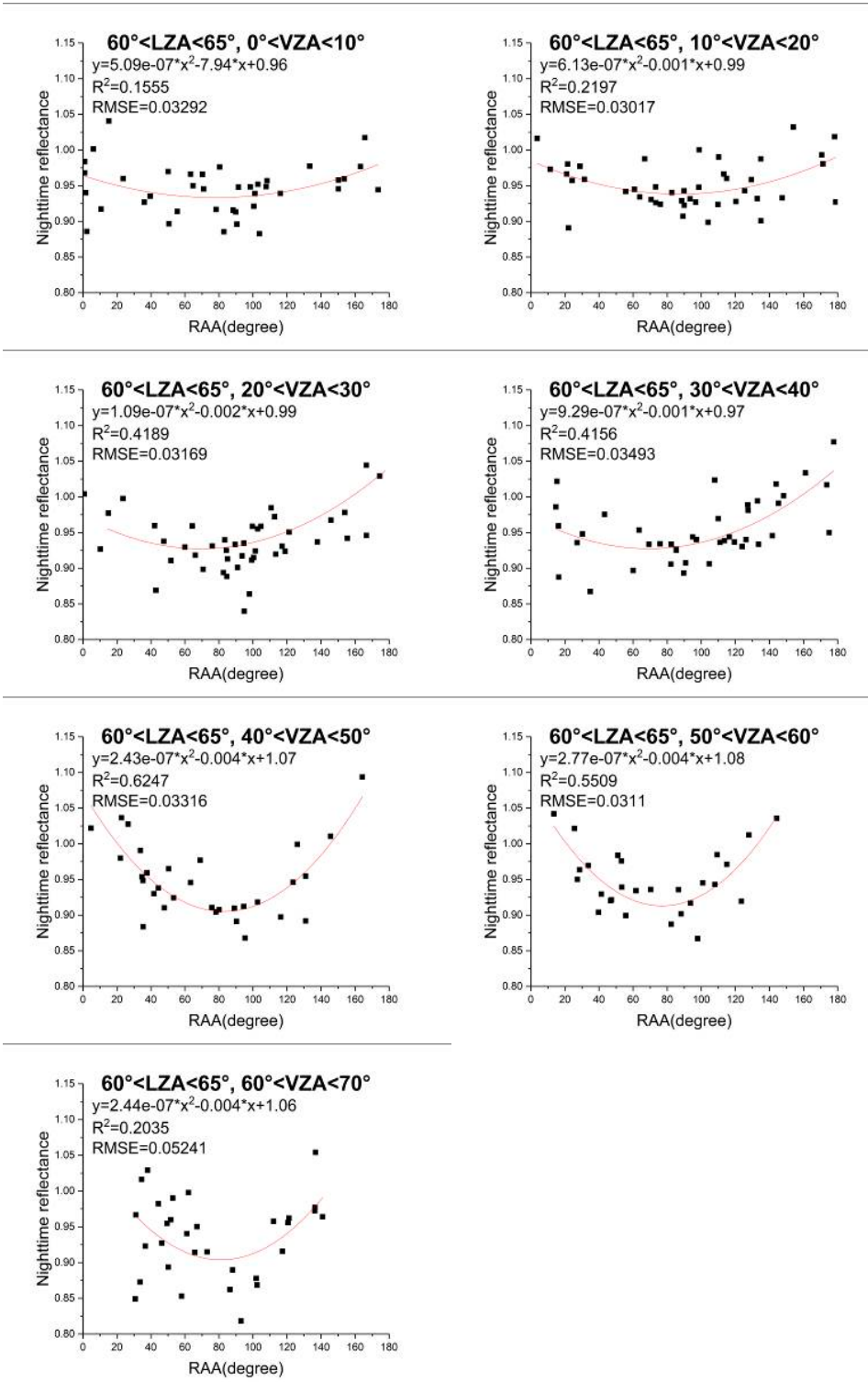

Figure 19. The relationship between nighttime TOA reflectance and RAA, in nine years, under the selection criteria $\left(60^{\circ}<\mathrm{LZA}<65^{\circ}, 5^{\circ}<\mathrm{LPA}<70^{\circ}\right.$, and SZA $\left.>118.4^{\circ}\right)$. The red line denotes the result of polynomial fitting.

Therefore, within the margin of error of $0.55-2.77 \%$, these surface BRDF models are suitable for the nighttime TOA over Dome C. Warren and Hudson model both were developed exactly for Antarctic snow surface, and both consist of an ample number of parameters. In this article, based on the same ground measurements, they both have a good applicability on the nighttime TOA over Dome $C$ with higher correlation coefficients and lower RMSEs than RossLi BRDF model. The correlation coefficients of Warren model are between 0.9899 and 0.9945 always higher than RossLi BRDF and Hudson models. Moreover, the RMSEs of the Warren model are between 0.0383 and $0.0487 \mathrm{~W} \cdot \mathrm{cm}^{-2} \cdot \mathrm{sr}^{-1}$ always lower than RossLi BRDF and Hudson models. 

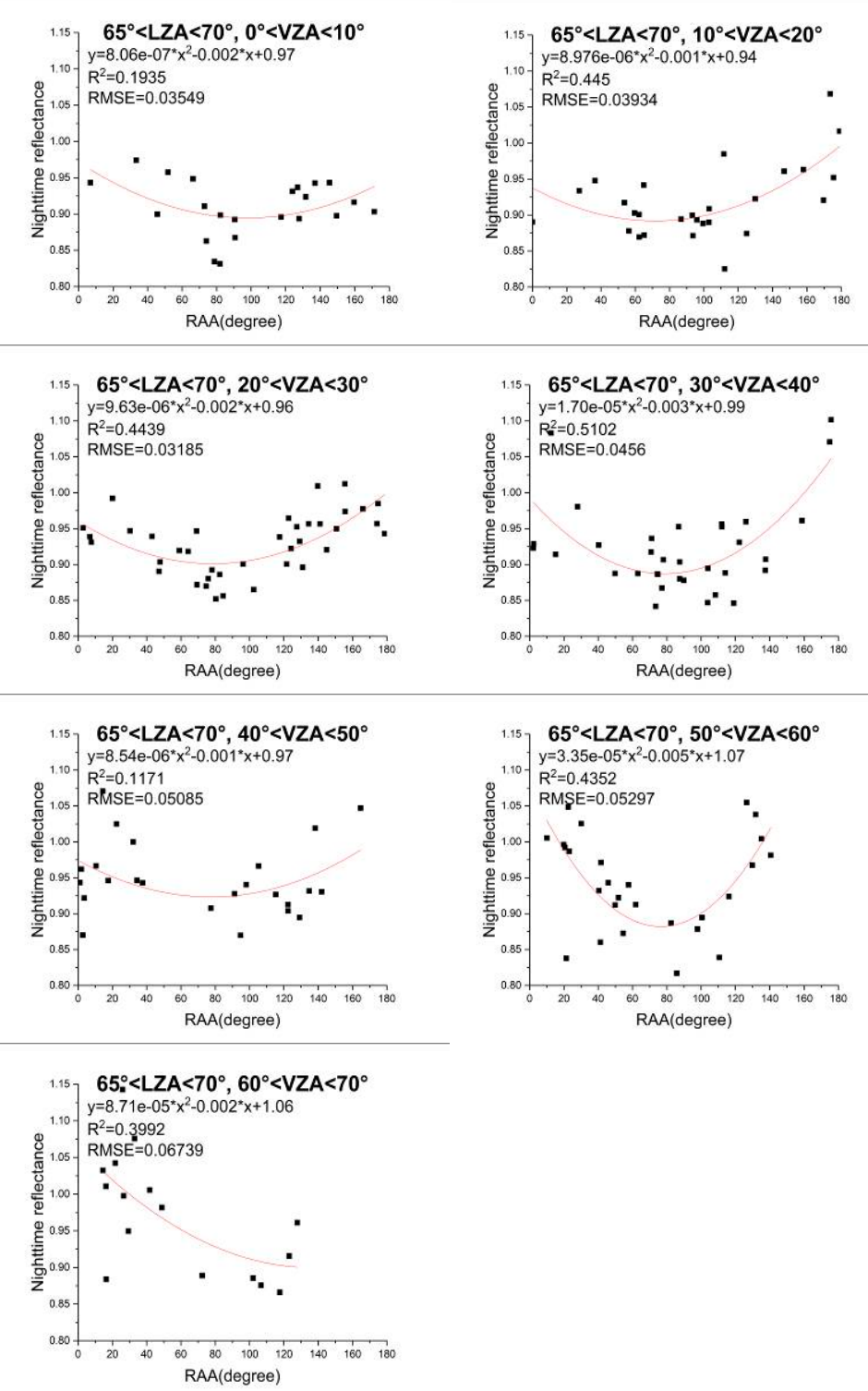

Figure 20. The relationship between nighttime TOA reflectance and RAA, in nine years, under the selection criteria $\left(65^{\circ}<\mathrm{LZA}<70^{\circ}, 5^{\circ}<\mathrm{LPA}<70^{\circ}\right.$, and SZA $\left.>118.4^{\circ}\right)$. The red line denotes the result of polynomial fitting. 

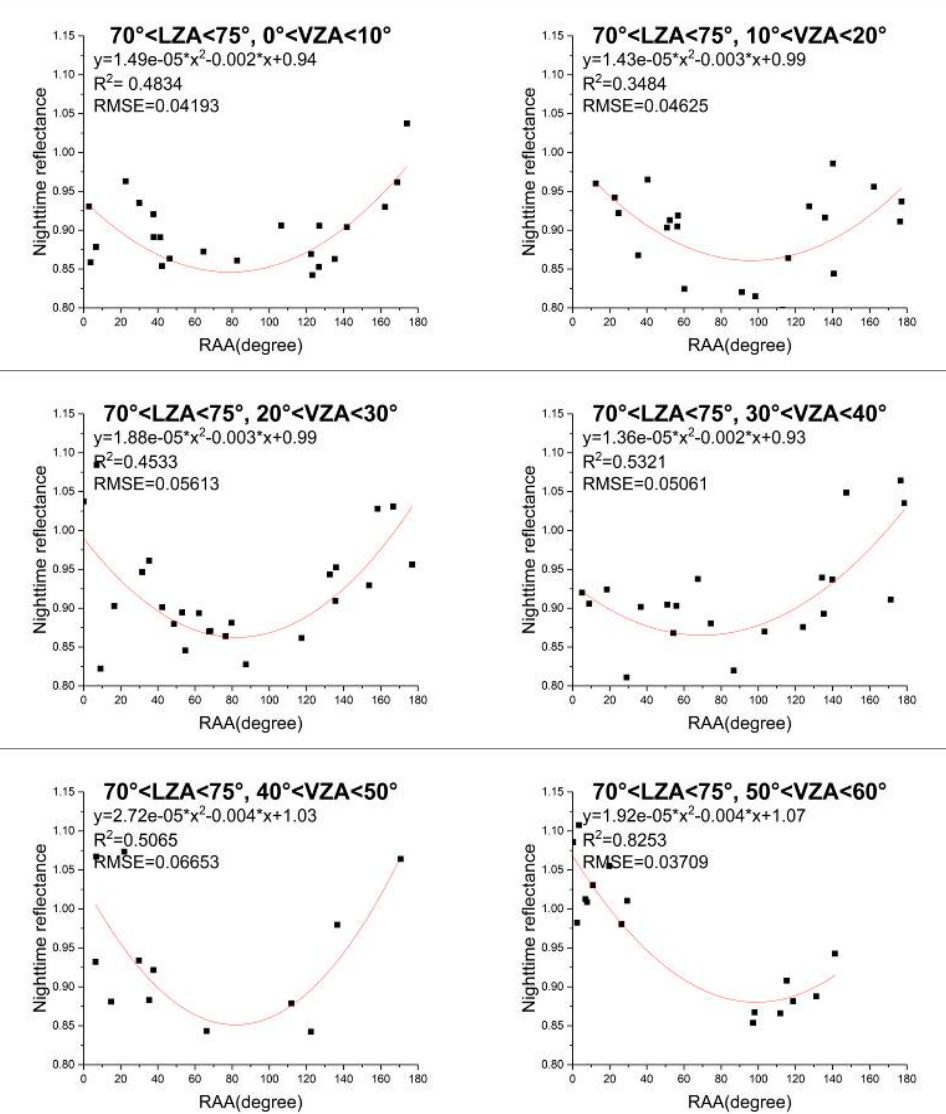

Figure 21. The relationship between nighttime TOA reflectance and RAA, in nine years, under the selection criteria $\left(70^{\circ}<\mathrm{LZA}<75^{\circ}, 5^{\circ}<\mathrm{LPA}<70^{\circ}\right.$, and SZA $\left.>118.4^{\circ}\right)$. The red line denotes the result of polynomial fitting.

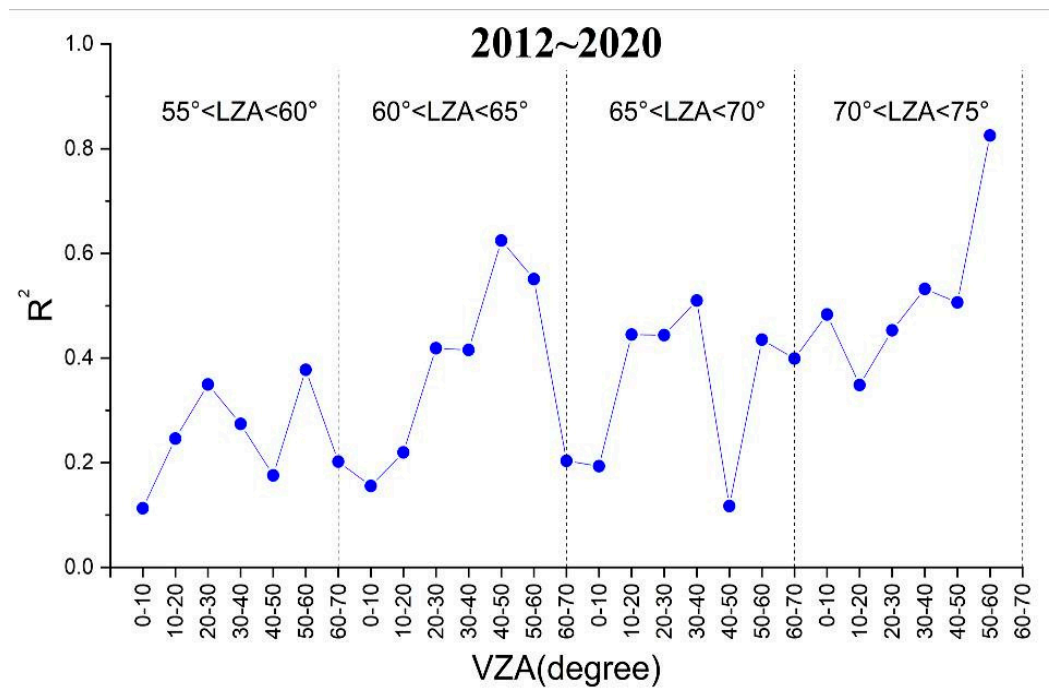

Figure 22. The correlation coefficient $\left(\mathrm{R}^{2}\right)$ of polynomial fitting of the previous 27 graphs (Figures 18 21). These values are in the same order as the graphs in Figures 18-21. The dotted black lines divide the results into the four groups. 


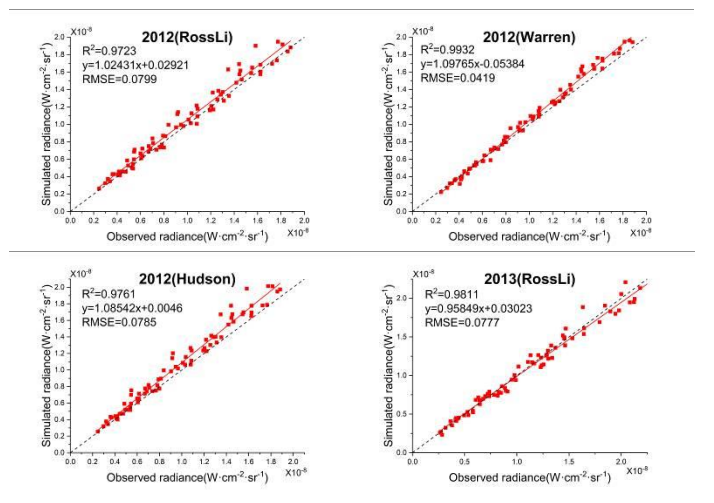

Figure 23. Cont.

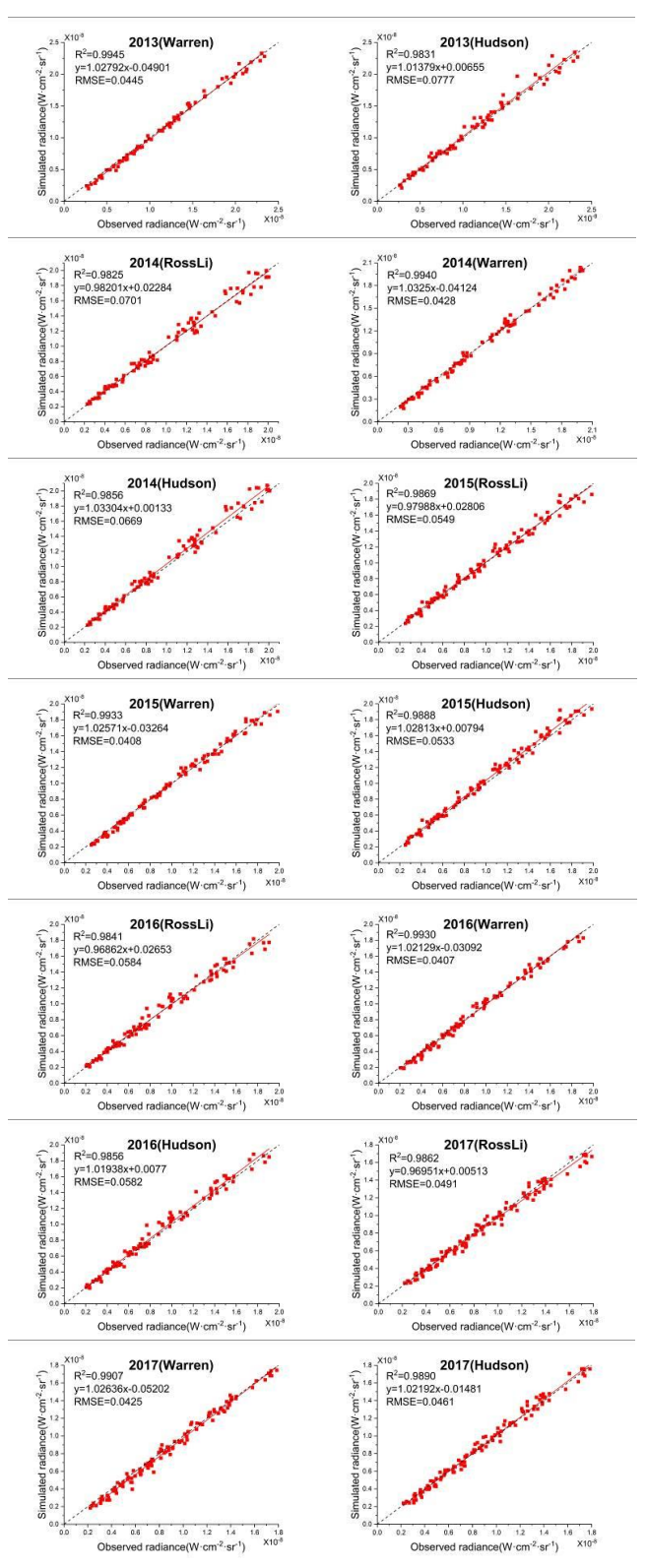

Figure 23. Cont. 


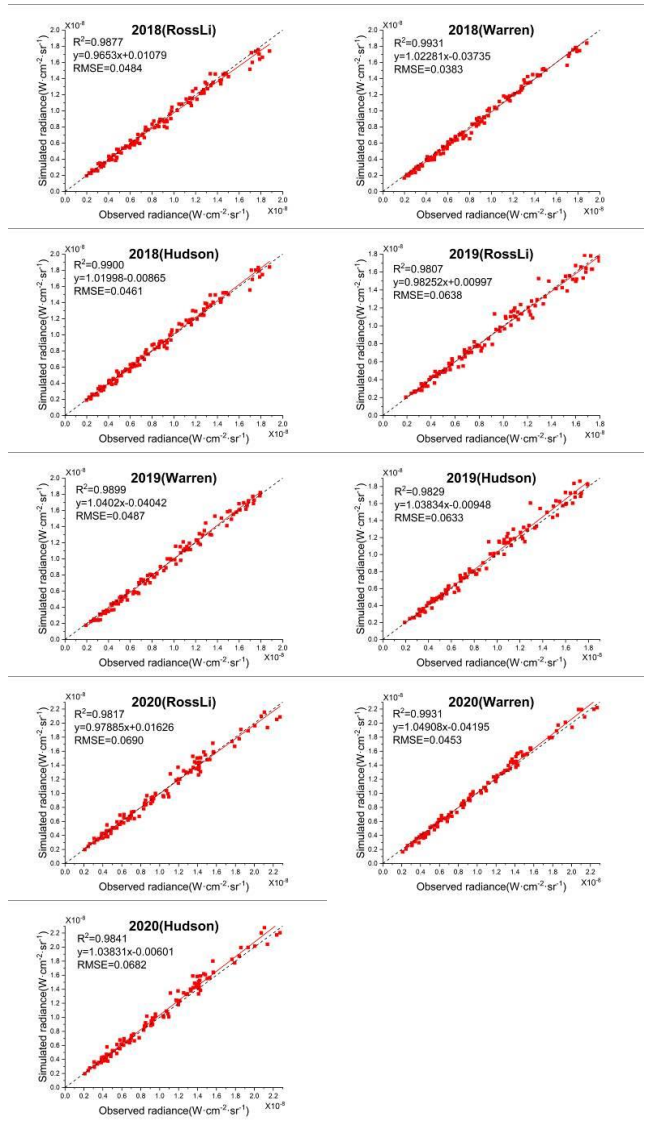

Figure 23. Comparison of the simulated nighttime radiance at satellite, respectively, using three surface BRDF models and the observed radiance during 2012-2020. Note: The unit of radiance is W $\mathrm{cm}^{-2} \mathrm{sr}^{-1}$. The red solid lines are the results of liner fitting.

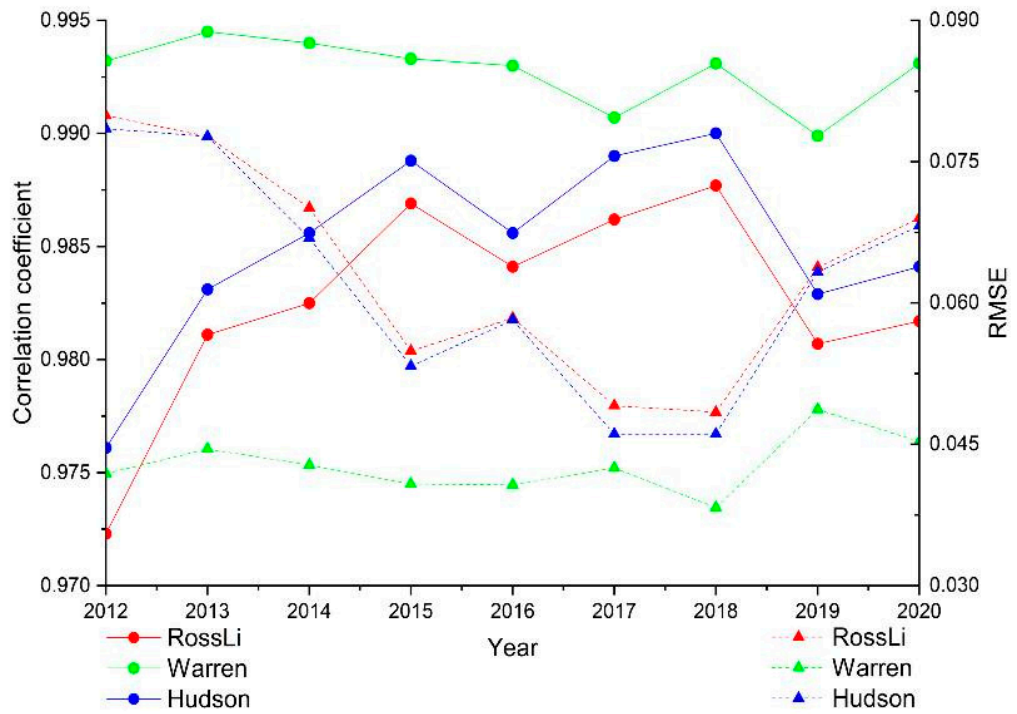

Figure 24. Variation of the correlation coefficients and the RMSE over the years between the simulated nighttime radiance at satellite, respectively, using three surface BRDF models and the observed radiance.

\section{Conclusions}

In this study, based on the variable-controlling approach, the effect of three angles (LZA, VZA, and RAA) on nighttime TOA reflectance were analyzed over Dome $\mathrm{C}$, from the 
year 2012 to 2020, and it was found that different angles in different ranges have different influences on the reflectance. (1) When LZA is less than $65^{\circ}$, the reflectance tends to decrease with the increase of VZA. When LZA is higher than $65^{\circ}$, the reflectance increases with VZA. (2) Only when the VZA is in $50^{\circ}-60^{\circ}$ and RAA is less than $30^{\circ}$, or VZA is in $60^{\circ}$ $70^{\circ}$ and RAA is in $90^{\circ}-120^{\circ}$, the nighttime TOA reflectance is positively correlated with the LZA. In other cases, the reflectance is negatively correlated with the LZA. (3) The forward scattering and backward scattering are not symmetric at night. On the other hand, three BRDF models were, respectively, used to explore the applicability of surface BRDF models at nighttime TOA, and all of these models have an excellent and suitable performance. The correlation coefficient in descending order each year is Warren $>$ Hudson $>$ RossLi, and the RMSE, in ascending order, each year, is Warren $<$ Hudson $<$ RossLi. Especially, the correlation coefficients and RMSEs of Warren model are always higher than 0.9899 and less than $0.0487 \mathrm{~W} \cdot \mathrm{cm}^{-2} \cdot \mathrm{sr}^{-1}$, respectively.

Although the Dome $C$ has been considered as an ideal ground site for the calibration and validation of satellite sensors, there is a large nighttime variation in reflectance, due to the impact of the BRDF. Results show that bidirectional nighttime reflectance variation is very sensitive when LZA exceeds 70 degrees or VZA is lower than 10 degrees, which is therefore not recommended to conduct the evaluation of VIIRS DNB HGS calibration across satellite over Dome C. Besides, this study provided three TOA reflectance models which can be used to track the radiometric calibration stability and consistency of nighttime satellite sensors over Dome $\mathrm{C}$, especially for those scanning imagers acquiring large angular views. With comparisons between three BRDF models, the findings can be expected to improve the accuracy of radiometric inter-comparisons among various sensors in the nighttime remote sensing.

Author Contributions: J.L. downloaded the satellite data, analyzed the results, and wrote the paper; S.Q., Y.Z. (Yu Zhang) and B.Y. conceived of and designed the experiments; S.Q. edited this paper; C.G., Y.Q., Y.L. and Y.Z. (Yongguang Zhao) reviewed the paper. All authors have read and agreed to the published version of the manuscript.

Funding: This research was funded by the Bureau of International Co-Operation Chinese Academy of Sciences (Grant No. 181811KYSB20160040), Key Research Program of Frontier Sciences, CAS, Grant No. QYZDB-SSW-JSC051, and the National Natural Science Foundation of China, under Grant $61,801,457$ and 41875042 . And the APC was funded by the National Natural Science Foundation of China, under Grant 61,801,457.

Data Availability Statement: The data presented in this study are openly available in Hudson et al. [19].

Acknowledgments: We thank the NOAA's Comprehensive Large Array-Data Stewardship System for providing the S-NPP VIIRS DNB data that are available online. The comments and recommendations by the anonymous reviewers are also greatly appreciated.

Conflicts of Interest: The authors declare no conflict of interest.

\section{References}

1. Liao, L.; Weiss, S.; Mills, S.; Hauss, B. Suomi NPP VIIRS day-night band on-orbit performance. J. Geophys. Res. Atmos. 2013, 118, 12705-12718. [CrossRef]

2. Lee, S.; McIntire, J.; Oudrari, H.; Schwarting, T.; Xiong, X. A New Method for Suomi-NPP VIIRS Day-Night Band on-Orbit Radiometric Calibration. IEEE Trans. Geosci. Remote Sens. 2015, 53, 324-334. [CrossRef]

3. Lee, S.; Chiang, K.; Xiong, X.; Sun, C.; Anderson, S. The S-NPP VIIRS Day-Night Band On-Orbit Calibration/Characterization and Current State of SDR Products. Remote Sens. 2014, 6, 12427-12446. [CrossRef]

4. Mills, S.; Weiss, S.; Liang, C. VIIRS day/night band (DNB) stray light characterization and correction. Proc. SPIE 2013, 8866, 1-18. [CrossRef]

5. Ma, S.; Yan, W.; Huang, Y.; Ai, W.; Zhao, X. Vicarious calibration of S-NPP/VIIRS day-night band using deep convective clouds. Remote Sens. Environ. 2014, 158, 42-55. [CrossRef]

6. Cao, C.; Bai, Y.; Wang, W.; Choi, T. Radiometric Inter-Consistency of VIIRS DNB on Suomi NPP and NOAA-20 from Observations of Reflected Lunar Lights over Deep Convective Clouds. Remote Sens. 2019, 11, 934. [CrossRef]

7. Román, M.O.; Wang, Z.; Sun, Q.; Kalb, V.; Miller, S.D.; Molthan, A.; Schultz, L.; Bell, J.; Stokes, E.C.; Pandey, B.; et al. NASA’s Black Marble nighttime lights product suite. Remote Sens. Environ. 2018, 210, 113-143. [CrossRef] 
8. Roujean, J.; Leroy, M.; Deschamps, P. A bidirectional reflectance model of the Earth's surface for the correction of remote sensing data. J. Geophys. Res. 1992, 97, 20455-20468. [CrossRef]

9. Ni, W.; Li, X. A Coupled Vegetation-Soil Bidirectional Reflectance Model for a Semiarid Landscape. Remote Sens. Environ. 2000, 74, 113-124. [CrossRef]

10. Vermote, E.; Justice, C.; Bréon, F. Towards a Generalized Approach for Correction of the BRDF Effect in MODIS Directional Reflectances. IEEE Trans. Geosci. Remote Sens. 2009, 47, 898-980. [CrossRef]

11. Zhang, X.; Wang, J.; Henebry, J.; Gao, F. Development and evaluation of a new algorithm for detecting $30 \mathrm{~m}$ land surface phenology from VIIRS and HLS time series. ISPRS J. Photogramm. 2020, 161, 37-51. [CrossRef]

12. Li, C.; Xue, Y.; Liu, Q.; Ouazzane, K.; Zhang, J. Using SeaWiFS Measurements to Evaluate Radiometric Stability of PseudoInvariant Calibration Sites at Top of Atmosphere. IEEE Geosci. Remote. Sens. Lett. 2015, 12, 125-129. [CrossRef]

13. Doherty, S.; Warren, S. The Antarctic and Greenland snow surfaces as calibration targets for the visible channel of the Advanced Very High Resolution Radiometer. Proc. IEEE Int. Geosci. Remote Sens. Symp. 1998, 4, 2267-2269. [CrossRef]

14. Jiao, Z.; Ding, A.; Kokhanovsky, A.; Schaaf, C.; Bréon, F.; Dong, Y.; Wang, Z.; Liu, Y.; Zhang, X.; Yin, S.; et al. Development of a snow kernel to better model the anisotropic reflectance of pure snow in a kernel-driven BRDF model framework. Remote Sens. Environ. 2019, 221, 189-209. [CrossRef]

15. Walther, A.; Heidinger, A.; Miller, S. The expected performance of cloud optical and microphysical properties derived from Suomi NPP VIIRS day/night band lunar reflectance. J. Geophys. Res. Atmos. 2013, 118, 13230-13240. [CrossRef]

16. Cao, C.; Uprety, S.; Xiong, J.; Wu, A.; Jing, P.; Smith, D.; Chander, G.; Fox, N.; Ungar, S. Establishing the Antarctic Dome C community reference standard site towards consistent measurements from Earth observation satellites. Can. J. Remote Sens. 2014, 36, 498-513. [CrossRef]

17. Chen, X.; Wu, A.; Xiong, X.; Lei, N.; Wang, Z.; Chiang, K. Using Ground Targets to Validate S-NPP VIIRS Day-Night Band Calibration. Remote Sens. 2016, 8, 984. [CrossRef]

18. Warren, S.; Brandt, R.; Hinton, P. Effect of surface roughness on bidirectional reflectance of Antarctic snow. J. Geophys. Res. 1998, 103, 25789-25807. [CrossRef]

19. Hudson, S.; Warren, S.; Brandt, R.; Grenfell, T.; Six, D. Spectral bidirectional reflectance of Antarctic snow: Measurements and parameterization. J. Geophys. Res. 2006, 111,1-19. [CrossRef]

20. Baker, N. Joint Polar Satellite System (JPSS) VIIRS Radiometric Calibration Algorithm Theoretical Basis Document (ATBD), Revision C; Goddard Space Flight Center: Greenbelt, MD, USA, 2013.

21. Qiu, S.; Shao, X.; Cao, C.; Uprety, S.; Wang, W. Assessment of straylight correction performance for the VIIRS Day/Night Band using Dome-C and Greenland under lunar illumination. Int. J. Remote Sens. 2017, 38, 5880-5898. [CrossRef]

22. Chen, H.; Sun, C.; Chen, X.; Chiang, K.; Xiong, X. On-orbit calibration and performance of S-NPP VIIRS DNB. Proc. SPIE 2016, 9881, 1-12. [CrossRef]

23. Lucht, W.; Schaaf, C.; Strahler, A. An algorithm for the retrieval of albedo from space using semi-empirical BRDF models. IEEE Trans. Geosci. Remote Sens. 2000, 38, 977-998. [CrossRef]

24. Lucht, W.; Roujean, J. Considerations in the parametric modeling of BRDF and albedo from multiangular satellite sensor observations. Remote Sens. Rev. 2000, 18, 343-379. [CrossRef]

25. Schaaf, C.; Gao, F.; Strahler, A.; Lucht, W.; Li, X.; Tsang, T.; Strugnell, N.; Zhang, X.; Jin, Y.; Muller, J. First operational BRDF, albedo nadir reflectance products from MODIS. Remote Sens. Environ. 2002, 83, 135-148. [CrossRef]

26. Román, M.; Schaaf, C.; Lewis, P.; Gao, F.; Anderson, G.; Privette, J.; Strahler, A.; Woodcock, C.; Barnsley, M. Assessing the coupling between surface albedo derived from MODIS and the fraction of diffuse skylight over spatially-characterized landscapes. Remote Sens. Environ. 2010, 114, 738-760. [CrossRef]

27. Ross, J.K. The Radiation Regime and Architecture of Plant Stands; Junk, W., Ed.; Dr W. Junk Publishers: Norwell, MA, USA, 1981; 392p.

28. Li, X.; Strahler, A.H. Geometric-optical bidirectional reflectance modeling of the discrete crown vegetation canopy: Effect of crown shape and mutual shadowing. IEEE Trans. Geosci. Remote Sens. 1992, 30, 276-292. [CrossRef]

29. Wu, A.; Xiong, X.; Cao, C.; Angal, A. Monitoring MODIS calibration stability of visible and near-IR bands from observed top-ofatmosphere BRDF-normalized reflectances over Libyan Desert and Antarctic surfaces. Proc. SPIE 2008, 7081, 1-9. [CrossRef]

30. Wu, A.; Xiong, X.; Cao, C. Assessment of stability of the response versus scan angle for the S-NPP VIIRS reflective solar bands using pseudo-invariant desert and Dome C sites. Proc. SPIE 2017, 10423, 1-9. [CrossRef]

31. Lucht, W. Expected retrieval accuracies of bidirectional reflectance and albedo from EOS-MODIS and MISR angular sampling. J. Geophys. Res. 1998, 103, 8763-8778. [CrossRef]

32. Huang, X.; Jiao, Z.; Dong, Y.; Zhang, H.; Li, X. Analysis of BRDF and Albedo Retrieved by Kernel-Driven Models Using Field Measurements. IEEE J. Stars. 2013, 6, 149-161. [CrossRef]

33. Strahler, A.; Muller, J.; Lucht, W.; Schaaf, C.; Tsang, T.; Gao, F.; Li, X.; Lewis, P.; Barnsley, M. MODIS BRDF/Albedo Product: Algorithm Theoretical Basis Document Version 5.0. MODIS Doc. 1999, 23, 42-47.

34. Miller, S.; Turner, R. A Dynamic Lunar Spectral Irradiance Data Set for NPOESS/VIIRS Day/Night Band Nighttime Environmental Applications. IEEE Trans. Geosci. Remote Sens. 2009, 47, 2316-2329. [CrossRef]

35. Wu, A.; Xiong, X.; Cao, C. Examination of Calibration Performance of NOAA KLM AVHRR Using Measurements over the Dome C Site in Antarctica. Proc. SPIE 2008, 7106, 1-10. [CrossRef] 
36. Helder, D.; Thome, K.; Mishra, N.; Chander, G.; Xiong, X.; Angal, A.; Choi, T. Absolute Radiometric Calibration of Landsat Using a Pseudo Invariant Calibration Site. IEEE Trans. Geosci. Remote Sens. 2013, 51, 1360-1369. [CrossRef]

37. Loeb, N. In-flight calibration of NOAA AVHRR visible and near-IR bands over Greenland and Antarctica. Int. J. Remote Sens. 1997, 18, 477-490. [CrossRef]

38. Masonis, S.; Warren, S. Gain of the AVHRR visible channel as tracked using bidirectional reflectance of Antarctic and Greenland snow. Int. J. Remote Sens. 2001, 22, 1495-1520. [CrossRef]

39. Six, D.; Fily, M.; Alvain, S.; Henry, P.; Benoist, J. Surface characterisation of the Dome Concordia area (Antarctica) as a potential satellite calibration site, using Spot 4/Vegetation instrument. Remote Sens. Environ. 2004, 89, 83-94. [CrossRef]

40. Walden, V.; Roth, W.; Stone, R.; Halter, B. Radiometric validation of the Atmospheric Infrared Sounder over the Antarctic Plateau. J. Geophys. Res. 2006, 111, 1-13. [CrossRef]

41. Jaross, G.; Warner, J. Use of Antarctica for validating reflected solar radiation measured by satellite sensors. J. Geophys. Res. 2008, 113, 1-13. [CrossRef]

42. Wenny, B.; Xiong, X. Using a Cold Earth Surface Target to Characterize Long-Term Stability of the MODIS Thermal Emissive Bands. IEEE Geosci. Remote. Sens. Lett. 2008, 5, 162-165. [CrossRef]

43. Uprety, S.; Cao, C. A comparison of the Antarctic Dome C and Sonoran Desert sites for the cal/val of visible and near infrared radiometers. Proc. SPIE 2010, 7811, 1-10. [CrossRef]

44. Uprety, S.; Cao, C. Radiometric and spectral characterization and comparison of the Antarctic Dome C and Sonoran Desert sites for the calibration and validation of visible and near-infrared radiometers. J. Appl. Remote Sens. 2012, 6, 063541. [CrossRef]

45. Uprety, S.; Cao, C. Suomi NPP VIIRS reflective solar band on-orbit radiometric stability and accuracy assessment using desert and Antarctica Dome C sites. Remote Sens. Environ. 2015, 166, 106-115. [CrossRef]

46. Zeng, X.; Shao, X.; Qiu, S.; Ma, L.; Gao, C.; Li, C. Stability Monitoring of the VIIRS Day/Night Band over Dome C with a Lunar Irradiance Model and BRDF Correction. Remote Sens. 2018, 10, 189. [CrossRef]

47. Shao, X.; Cao, C.; Uprety, S. Vicarious Calibration of S-NPP/VIIRS Day-Night Band. Proc. SPIE 2013, 8866, 88661S. [CrossRef]

48. Hapke, B.; Nelson, R.; Smythe, W. The Opposition Effect of the Moon: The Contribution of Coherent Backscatter. Science 1993, 260, 509-511. [CrossRef] [PubMed]

49. Qiu, S.; Shao, X.; Cao, C.; Uprety, S. Feasibility demonstration for calibrating Suomi-National Polar-Orbiting Partnership Visible Infrared Imaging Radiometer Suite day/night band using Dome C and Greenland under moon light. J. Appl. Remote Sens. 2016, 10, 016024. [CrossRef] 